\title{
Inequality and Finance in a Rent Economy
}

\author{
Alberto Botta \\ Eugenio Caverzasi \\ (University of Greenwich) \\ (Università Politecnica delle Marche) \\ Alberto Russo* \\ Mauro Gallegati \\ Joseph Stiglitz \\ (Università Politecnica delle Marche) \\ (Università Politecnica delle Marche) \\ (Columbia University)
}

This version: 15th December 2018

\begin{abstract}
The present paper aims at offering a contribution to the understanding of the interactions between finance and inequality. We investigate the ways through which income and wealth inequality may have influenced the development of modern financial systems in advanced economies, the US economy first and foremost, and how modern financial systems have then fed back on income and wealth distribution. We focus in particular on securitization and on the production of complex structured financial products. We analyse this topic by elaborating a hybrid Agent-Based Stock-Flow-Consistent (AB-SFC) macroeconomic model, encompassing heterogenous (i.e. households) and aggregate sectors. Our findings suggest that the increase in economic growth, favoured by the higher levels of credit supply coming with securitization, may determine a more unequal and financially unstable economic system. We also find that a lower degree of tax progressiveness and wider wage inequality further polarize income and wage distribution, and reduce economic growth.
\end{abstract}

*Corresponding address: Department of Management, Università Politecnica delle Marche, Piazzale Martelli 8, 60121 Ancona (Italy). E-mail: alberto.russo@univpm.it 


\section{Introduction}

There are two well-known stylised facts as to the evolution of most developed economies since the 1970s. First, most developed economies, in particular Anglo-Saxon economies such as the USA and the UK, have experienced a significant increase in income and wealth inequality (Stiglitz, 2016). Second, the financial sector expanded considerably, both in absolute and relative terms - with respect to the economy as a whole (Kumhof et al., 2015). Is there any causal link between these two facts? Does (expanding) finance carry out any effect on income and wealth distribution and vice versa?

Albeit being rather overlooked until recently, the possible relationship between finance and inequality is not a new topic in economics. It was first addressed by economists interested in understanding whether financial liberalization and financial development could reduce income inequality (Levine, 2005; Clarke et al., 2006; Beck et al., 2007). More recently, the outbreak of the financial crisis was interpreted as a hint that a reverse causality may also hold true. Indeed, several authors see in the increase in income and wealth inequality, and in its effects on households' debt, the real roots of the 2007-2008 financial shock (Fitoussi and Stiglitz, 2009; Stockhammer, 2015; Kumhof et al., 2015).

Both strands of analyses did not reach a clear-cut finding, either at theoretical or empirical level (see Bordo and Meissner, 2012, for a rejection of the 'inequality-leads-to-crisis' hypothesis). But regardless from the achievement of any consensus, what is still missing is a comprehensive overview of the likely endogenous and bidirectional relationship between finance and inequality. More specifically, we think that a relevant shortcoming of the existing contributions is the lack of a general portray of the ways income and wealth inequality may have influenced the development of financial systems in advanced economies, the US economy first and foremost, and how modern financial systems have then fed back on income and wealth distribution.

The present paper aims at offering a contribution in filling this gap. We do so by presenting a simple theoretical model about the reciprocal interaction between income and wealth distribution on the one hand, and the development of modern financial systems on the other hand. Financial systems have changed dramatically in the last three decades. Among the most relevant financial novelties, we focus on securitization and on the production of complex structured financial products (i.e. two distinguishing features of the so-called shadow banking) and the way they may interact with income and wealth inequality. We analyse this topic by elaborating a hybrid Agent-Based Stock-Flow-Consistent (AB-SFC) macroeconomic model, encompassing heterogenous (i.e. households) and aggregate sectors. Into this framework, we allow households to get access to bank lending in order to achieve their consumption goals as well as to accumulate financial assets in the form of shares of Investment Funds. Investment Funds, in turn, remunerate households' financial investments by allocating collected funds on different financial assets, namely risk-free low-remunerative government bonds and (relatively) riskier more remunerative structured financial products such as Collateralised Debt Obligations (CDOs). The production of CDOs as carried out by investment banks is ultimately meant to satisfy the demand for remunerative assets by (wealthy) households and is permitted by the endogenous securitization of (a part of) commercial banks' original loans to households and non-financial firms. Through the mechanisms of our model, we provide a formal description of the functioning of what Stiglitz (2015b) previously labelled as a rent-seeking or exploitation rent economy, i.e. an economic system in which the ultimate goal of credit creation is not the financing of productive activities whereas the remuneration of rent positions via the production of complex structured financial products, the securitization of existing loans, and, eventually, the over-indebtedness of low-middle income households.

In the aftermath of the financial crisis, an increasing number of $\mathrm{AB}$ models have started paying attention from different angles and with different purposes to the relationship between inequality, finance and economic performance, the last term here intended as economic growth and macroeconomic stability (Ciarli et al., 2012; Dosi et al., 2013; Russo et al., 2016; Cardaci and Saraceno, 2016; Fagiolo et al., 2017; Palagi et al., 2017; Cardaci, 2018). With respect to this body of literature, our analysis leads to three major innovations.

First, similarly to Cardaci and Saraceno (2016) and Cardaci (2018), in our model increasing inequality and wealth concentration may give rise to credit boom allowing low-middle income households to "keep up with the Joneses" despite of a more unequal wealth and income distribution. However, differently 
from Cardaci and Saraceno (2016) and Cardaci (2018), changes in income and wealth distribution are not portrayed (or not exclusively portrayed) as exogenous shocks. Quite the contrary, we describe income and wealth inequality as endogenous and co-evolving together with the development of shadow banking. In our model, securitization and CDOs spread in order to satisfy the appetite for high returns from (rentier) wealthy households. Financial systems accommodate such a demand for remunerative assets by allowing commercial banks to extend more loans to increasingly indebted households, and then by introducing newly created loans in the securitization process in order to produce CDOs. Given wage inequality, the stream of interest payments from low-middle income households and financial rents to top-income households exacerbates income and wealth inequality, and makes the conditions for the development of these new financial practices even stronger.

Second, our model provides a better qualitative description of the expansion of financial intermediation, which in some previous AB models has been generally labelled as "financialization" (Cardaci and Saraceno, 2016; Fagiolo et al., 2017). Fagiolo et al. (2017), for instance, identify financialization with the total amount of loans over GDP. Cardaci and Saraceno (2016) adopt the same perspective. In their model, financialization, read a higher credit-to-GDP ratio, is the result of an exogenous change in the risk aversion parameter governing the behaviour of financial actors. Whilst the rise in the ratio between credit and GDP can certainly be considered as a distinguishing feature if not a symptom of financialization, there is no doubt that financialization is a much broader phenomenon (Epstein, 2005). Following Botta et al. (2018), in this paper we take a step further, by describing, in the context of an AB model, how new financial practices and products have effectively allowed for the over-expansion of the credit activity. In our model, this happens thanks to the production of structured financial products (CDOs), which is based on the securitization of loans. The demand-led provision of financial commodities (i.e. securitised loans) in turn enables commercial banks to unburden their balance sheet and to engage in a more aggressive creation of new loans. Other way around, in the present model we endogenise the behaviour of the financial sector as to the capacity to create financial products, the capacity to manage their leverage and capital requirements, ultimately their propensity to risk.

Third, consistently with Russo et al. (2016), Cardaci and Saraceno (2016) and Cardaci (2018), we maintain that credit booms and shadow banking mechanisms may compensate for the detrimental effects that higher inequality may bear on economic activity via a lower aggregate demand (see Dosi et al., 2013; Palagi et al., 2017), and actually lead to a sort of finance-led growth regime (Boyer, 2010). However, such a seemingly positive relationship between finance and economic growth comes at the cost of a more unstable macroeconomic environment with a higher probability of endogenously generated deep financial and economic crises. ${ }^{1}$ In our model, after an initial phase of credit boom and vigorous economic growth, overindebted low-middle class households may ultimately default on their payments commitments. This event first causes the reduction of the remunerativeness of CDOs and of Investment Funds' shares. Secondly, it induces the dry-up of the demand for structured financial products, the flight to safe assets (e.g. government bonds) by investment funds, eventually the break-down of the securitizing system (Gorton and Metrick, 2012) and the end of the credit boom securitization previously allowed for. In this sense, our model is consistent with the empirical evidence from the last financial crisis, which shows how restrictions to the provision of credit (if not a credit crunch) and the freezing of financial markets are distinguishing features of the financial crisis itself and causes of the ensuing economic downturn. ${ }^{2}$

\footnotetext{
${ }^{1}$ Our work represents a different but complementary contribution with respect to those enquiring the long-run effects that the over-expansion of the financial sector may have on the functioning of modern economies (see Ciarli et al. (2012); Cecchetti and Kharroubi (2012); Dosi et al. (2013); Law and Singh (2014); Arcand et al. (2015); Fagiolo et al. (2017)). Similarly to previous AB models by Russo et al. (2016), Cardaci and Saraceno (2016), and Cardaci (2018), our attention is about pure macroeconomic dynamics and its stability. For the sake of simplicity, in this model we keep the non-financial productive side of the economy as simple as possible by taking it as a macro-aggregated sector that does not perform any innovation activity. Accordingly, we do not pay attention to the long-lasting effects that "too much finance" can certainly have on long-run growth by causing a misallocation of resources (see Cecchetti and Kharroubi (2012); Arcand et al. (2015)), by changing the composition of aggregate demand (see Ciarli et al. (2012)), or by over-financing uncertain innovation activities with respect to current production (Fagiolo et al., 2017). Differently from the above-mentioned AB models, our work offers a richer description of the mechanisms leading to the eruption and propagation of the crisis, in particular as far as credit creation and portfolio decisions of financial actors are concerned.

${ }^{2}$ The fragility and weak sustainability of such a self-feeding development process is also due to the fact that the risk associated to 'financial primary commodities', read subprime mortgages, may have been diluted into apparently safer structured financial products, but an increasing body of over-indebted households is still there, so that systemic financial
} 
In the final part of the paper, we run a variety of experiments about different taxation regimes: (i) a flat tax regime with a unique tax rate; (ii) a more progressive taxation; (iii) the introduction of a tax on financial wealth; (iv) the introduction of a tax on commercial banks' financial profits. Moreover, we enquire the effects of a higher level of exogenous wage inequality. Our findings suggest that higher exogenous wage inequality, as well as the introduction of the flat tax and the reduction in the progressiveness of income taxation is detrimental for growth. On top of this, the introduction of taxes on financial wealth and on financial profits leads to a significant squeeze of public deficit, to a reduction in the supply of safe financial assets (e.g. government bonds), and to a decrease in the corresponding yields. Interestingly, in our "rentier-friendly" economy, the financial sector will respond to such changes by expanding the production of self-made more remunerative but eventually riskier financial products (e.g. CDOs and securitised loans). In the end, the downsizing of the public sector seems to come with the risk of a more buoyant but more unstable finance-led economy.

More in general, the self-reinforcing although destabilising (in a Minskyan sense) process we describe in this paper lies at the basis of the macroeconomic evolution of most developed economies since the 1970s. By describing this process, our work offers an innovative contribution to the recent body of literature on the causes and consequences of the increasing levels of income and wealth inequality in advanced financialised economies over the last three decades (e.g. Atkinson et al., 2011; Piketty, 2014; Stiglitz, 2012, 2015a, 2016).

\section{Literature review}

There is an open debate in the economic literature about the relationship between inequality and finance. A first bunch of contributions on this topic takes somehow inspiration from the literature about financial repression. The focus here is on whether financial deregulation (i.e. the removal of controls and restrictions to the operativeness of financial operators) and/or financial development (i.e. the quantity of resources provided by the banking system to economic actors) may contribute to reduce income inequality. Some initial responses to this research question are on the positive (see, for instance Clarke et al., 2006; Beck et al., 2007; Abiad et al., 2008), as Levine (2005) himself stresses by stating that 'the results indicate that finance exerts a disproportionately large, positive impact on the poor and hence reduces income inequality' (Levine, 2005, p.920). The logic behind this perspective is quite simple. Financial liberalization, and the ensuing financial development, will allow financial operators to extend credit to those economic agents, usually the poor, which were previously cut off from external finance due to lack of acceptable collaterals and/or the imposition of a too restrictive regulation of financial activity. A wider access to external finance will in turn allow more people to accumulate human and/or physical capital, with obvious positive consequences as to income generation and the creation of a more equitable economic environment.

The above virtuous causality nexus running from (more) finance to (less) income inequality is not undisputed however. On the one hand, some authors have made the positive effect of financial liberalization and financial development on income inequality conditional to the presence of good economic and political institutions (Rajan and Zingales, 2003; Claessens and Perotti, 2007). Indeed, good institutions, which ensure sound economic competition, transparency and accountability are fundamental to ensure that financial development does not boil down to the mere concentration and capture of increasing financial resources by a restricted elite of well-connected actors. On the other hand, some recent empirical contributions find a negative effect of finance on income inequality (Denk and Cournede, 2015; de Haan and Sturm, 2017). And indeed these last findings seem consistent with the broad long-run analysis of income distribution provided by Piketty (2014). The fact that income distribution worsened the most in those Anglosaxon countries, namely the USA and the UK, which experienced a significant expansion of the financial sectors since the 1970s, that an increasing part of the income of top earners is made up by capital income, and, finally, that access to financial markets as intermediated by professional financial investors (read Investment Funds) allow wealthy households to get higher-than-average returns on capital are clear symptoms if not proofs that finance can actually play a negative effect on income inequality.

risk may have even increased. Interestingly, Wojnilower (1980) defines as 'paradox of risk' (from Keynes' paradox of thrift) the dynamics for which the availability of individual risk cover leads to higher systemic risk. 
Besides the effects that financial liberalization and financial development can bring about on inequality, there is a growing interest in investigating the inverse causality link running from inequality to finance. The outbreak of the last worldwide financial crisis significantly stimulated the emerge of a new strand of literature explaining the occurrence of the 2007-2008 financial shock as the long-term outcome of mounting inequality. There are several different interpretations of the most proximate causes of the 20072008 financial shock. Blanchard (2009) and Brunnermeir (2009) focus on some characteristic aspects of modern financial systems (however without connection with real-economy dynamics). They blame the spread of securitization, the production of opaque structured financial products, and the intricate network these practices gave rise as the most relevant factors transforming financial distress in a relatively tiny segment of financial markets (the market for subprime mortgages) in a full-blown systemic financial crisis. Taylor (2009) stresses that policy mistakes, in particular a too lax monetary policy and excessive governmental support to mortgage lending, ignited and fed the development of a boom in the housing market that eventually went bust. Despite these analyses capture some factors that contributed to heightened financial fragility, they neglect to frame them in a broader picture that connects those factors with the recent structural evolution of advanced economies, rising inequality first and foremost. Fitoussi and Stiglitz (2009) stress this point very clearly when they state that 'the crisis has structural roots' and that these roots consist in 'the structural changes in income distribution'. Indeed, 'since 1980, in most advanced countries the median wage has stagnated and inequalities have surged in favour of higher incomes [...]. In the US the compression of low incomes was compensated by the reduction of household savings and by mounting indebtedness that allowed spending patterns to kept virtually unchanged [so that] growth was maintained at the price of increasing public and private indebtedness' (Fitoussi and Stiglitz, 2009, pp.3-4).

Rajan (2010), Lysandrou (2011), Goda and Lysandrou (2014), van Treeck (2014), Stockhammer (2015), Kumhof et al. (2015), Russo et al. (2016), Cardaci and Saraceno (2016) and Cardaci (2018) all share a similar perspective. Rising inequality is to be considered the real cause of the crisis since that it generated, directly or indirectly, the quest for a credit-led (consumption and asset price) boom and the conditions for mounting households' indebtedness. Rajan (2010) stresses that such a perverse causality link from inequality to finance has been vitally intermediated by politics and political decisions. Fitoussi and Saraceno (2010) propose a similar point of view, in the sense that they bring the level of the analysis to monetary policy. In their view, monetary authorities endogenously took an accommodating stance in order to avoid a permanent (inequality-led) deficiency of aggregate demand, but excessive expansionary monetary policy ultimately corroborated an unsustainable credit boom and housing bubble. The starting point of Rajan's and Fitoussi and Saraceno's analyses is the increasing demand for loans coming from impoverished low-middle class households in order to compensate for stagnant wages and maintaine high consumption levels. Lysandrou (2011), and Goda and Lysandrou (2014) see this story from the opposite angle. It was the concentration of wealth in the hands of a few super rich, and the ensuing rise in the demand of remunerative financial assets, that induced the hypertrophic expansion of the financial sector and the production of structured financial products, of which banks' loans given to low-middle class households constituted the primary inputs. ${ }^{3}$

It is worth noting that Kumhof et al. (2015) integrate the above two aspects in a formal DSGE model. In their model, households at the bottom part of the income distribution increase their demand for external finance in order to 'keep up with the Joneses'. At the same time, wealthy households at the top of the distribution respond to such a demand by increasing the supply of loanable funds. This appreciable aspect notwithstanding, Kumhof's model misses to provide even a rough description of the financial mechanisms, better to say financial developments, that allowed the matching between the increasing demand for financial assets (supply of funds) from the better off and the higher demand for loans (demand of funds) from the worse off. This shortcoming is not trivial. On the one hand, the proliferation of remunerative, although allegedly safe, structured financial products (CDOs) meant to

\footnotetext{
${ }^{3}$ Stockhammer (2015) makes a similar point when he stresses that "increasing inequality has increased the propensity to speculate, that is, it has led to a shift to more risky financial assets. One particular aspect of these developments is that subprime derivatives, the segment where the financial crisis broke out in 2008, were developed to cater to the demands of hedge funds that manage the assets of the super-rich. Increasing inequality has thus played a role in the origin of the imbalances that erupted in the crisis as well as in the demand for the very assets in which the crisis broke out." (Stockhammer, 2015, pp.950-651).
} 
satisfy the 'appetite for rents' from wealthy households could only take place with the securitization of part of the stock of loans traditionally generated by commercial banks. On the other hand, commercial banks could easily satisfy the application for loans from indebted households and firms, and expand the stock of primary commodities for the production of CDOs, only by unburdening their asset position and offloading part of the existing assets out of their balance sheets and into the whirling securitization process. On top of this, it is also through this complex network of financial mechanisms that income and wealth have been regressively redistributed away from low-middle class to rich households. The development of securitization and structured financial products stands out as the endogenous response to the structural rise in inequality in advanced economies, and worked to make such trends even more acute. Rising inequality and securitization jointly contributed to the run-up towards the 2007-2008 financial crisis. This is why a deep understanding of the complex relationship between inequality and finance cannot depart from taking these two aspect together.

\section{A formal model of an exploitation rent economy}

The increase in the wealth-income ratio is a well-known stylised fact characterising advanced economies in the last three decades. Stiglitz (2016) explains how such a relevant increase in the wealth-income ratio has taken place alongside a constant or even decreasing capital-income ratio. This is due to the fact that a sizeable part of wealth is not represented by 'produced machines', but rather by land or 'other ownership claims giving rise to rents' (Stiglitz, 2016, p.3) . Given this fact, Stiglitz (2016) shows that much of the recent growth in wealth is the result of the increase in different form of rents eventually reflected in the value of wealth itself.

A great deal of the activities giving rise to rents take place in the financial system (Stiglitz, 2012). There are several forms of rents. 'Exploitation' rent is the rent accruing to economic agents as a consequence of monopoly power and of the departure from a perfectly competitive world. The financial sector is the paradigmatic industry that can benefit of exploitation rents given the specific role it plays in the wider economic system. Financial operators generate and manage a huge amount of asymmetric information. They are at the centre of complex and often opaque networks, which certainly give rise to economic dynamics inconsistent with perfect competition. ${ }^{4}$ The recent development of the shadow banking system has further increased the capability of the financial sector to create rents for itself and for rich wealth owners. Financial institutions are recognised the privileged position of creating (or intermediating) financial resources allowing economic actors to take economic decisions. Through this activity, financial institutions simultaneously originate their own assets and the liabilities of the others. In the traditional 'originate-and-hold' financial system, banks themselves kept the originated assets on their own balance sheets. In the more recent 'originate-and-distribute', originated assets are eventually moved (perhaps figuratively in the form of asset-backed securities and collateralised debt obligation) onto the balance sheet of wealthy households. It is precisely the diffusion of this practice that allowed finance to considerably increase the total amount of liabilities and assets characterising the economy. ${ }^{5}$ Accordingly, the development of securitization appear as functional to the creation of a higher stock of liabilities for the poorer and, correspondingly, of wealth for the richer. While fuelled by inequality (through the demand of securitized assets from those better off and the indebtedness of those worst off), they contributed to exacerbate inequality even further by creating financial claims to be honoured by impoverished low-middle class households to the benefits of top-income households.

At the best of our knowledge, only a restricted bunch of papers has so far described the impact of securitization on the behaviour of the financial system as a whole, none of them connecting the development of securitization to rising inequality. Mazzocchetti et al. (2017) and Lauretta (2018) propose two $\mathrm{AB}$ models in which they try to describe the effects of securitization and the ensuing expansion in the provision of loans to the economy on growth and the business cycle. In their models, however, securitization

\footnotetext{
${ }^{4}$ It is precisely due to the complex tangle of relationships finance naturally gives rise, and of the harsh economy-wide consequences that might emerge from the break-down of these connections, that a 'unique' rent position characterises financial systems in the form of the implicit public guarantee acknowledged to 'too-big-to-fail' banks (see Stiglitz (2016)).

${ }^{5}$ According to the IMF (2009), an additional recent stylised fact of advanced countries is the spectacular increase in the outstanding amount of securities, which has been taking place since the 1980s
} 
is a supply-driven phenomenon (Mazzocchetti et al., 2017), ${ }^{6}$ or it amounts to a pure parametrical exercise (Lauretta, 2018), which does not show any form of endogeneity and co-evolution with the distribution of income and wealth. ${ }^{7}$ By doing so, these models do not capture a fundamental reason for the development of securitization, i.e. the attempt to satisfy the demand for remunerative assets by top-income households ${ }^{8}$. Nikolaidi (2015) elaborates a SFC model in which securitization allows commercial banks to enlarge credit provision to workers' households, which in turns rely upon incresing indebtedness in order to alleviate the effects of stagnating wages. In this sense, Nikolaidi (2015) successfully captures one aspect of recent distributive dynamics in advanced economies, i.e. wage stagnation. Nevertheless, the lack of heterogenous households does not allow Nikolaidi (2015) to properly measure how personal income and wealth inequality coevolved with the financialization of the economy. ${ }^{9}$

Differently from the contributions just mentioned, this paper puts the joint dynamics of inequality and finance at the centre of its analysis. In order to accomplish with our purpose, we elaborate a hybrid Agent Based Stock Flow Consistent (AB-SFC) macroeconomic model, with all sectors at macro-aggregated level but the households sector. On the one hand, this parsimonious use of agent-based modelling allows us to avoid considerable problems in the interpretation of simulation results that usually arise in fullyfledged agent-based macro models. On the other hand, it allows us to formally enquire, through the assumption of multiple heterogeneous households, how increasing income and wealth inequality and the development of securitizing financial systems relate each other. The assumption of heterogeneous households is fundamental for two reasons. First, it allows us to effectively track changes in personal income and wealth inequality. Secondly, it is essential to formally analyse the rationale of the securitizing banking systems, and the tendency to generate financial contagion and high systemic risks that the development of securitization and of the production of structured financial products inevitably brings with it. The understanding of the systemic risk-prone nature of such a 'macroeconomic regime' (rising inequality matched with the development of securitizing banking) cannot be reached within a macroaggregated analytical model, or even within a model with two classes of households. On the contrary, agent-based models can effectively shed light on the above-mentioned economic mechanisms and detect contagion dynamics in financial networks. We precisely want to exploit such a potential of agent-based models.

Tables A.1 and A.2 portray the macro-structure of our simple closed economy. It consists of six sectors: households, non-financial productive firms (NFFs), the government, commercial banks (CB), Special Purpose Vehicles (SPVs) and, ultimately, investment funds (IF). The core of our model lies in the interaction between the households sector and the overall financial system, CBs, SPVs, and IFs alike. We assume the households sector to be made up of $\mathrm{N}$ heterogenous family units, which differ among one another for their wealth (both their initial endowment and wealth accumulated through time) and disposable income. Each individual household receives a household-specific endogenous disposable income. This is given by two components. Each household first receives an exogenous net wage (out of taxes) from NFFs (more on this below). Secondly, households' disposable income relies upon net payments from the financial sector. In each period of the model, those households holding IFs' shares will receive financial rents. At the same time, if indebted, they will have to make interest payments to CBs (and indirectly to SPVs and IFs via the securitization chain) on their outstanding debt stock. The ensuing positive or negative net financial payments will contribute to increase or, alternatively, squeeze

\footnotetext{
${ }^{6}$ Mazzocchetti et al. (2017) assume commercial banks to securitize the amount of existing loans that will allow them to downsize their balance sheet and accomplish with capital requirements according to an exogenously set 'securitization propensity parameter' $\mu$. In their model, the supply of securitized assets may nevertheless respond endogenously to changes in the riskiness of loans given to firms, which is in turn affected by the business cycle

${ }^{7}$ Lauretta (2018) describes three different dynamics of the securitization process according to three different values of the 'financial innovation' parameter governing the securitization process itself.

${ }^{8}$ Goda and Lysandrou (2014) provide anecdotal evidence of the relevance of this aspect by quoting Charles Prince's (ex Citigroup CEO) testimony to the Financial Crisis Inquiry Commission. Prince said: "Securitization could be seen as a factory line. As more and more and more of these subprime mortgages were created as raw material for the securitization process" (Goda and Lysandrou, 2014, p. 102). In connection with Price's statement, Goda and Lysandrou (2014) also quote Mike Francis, executive director at Morgan Stanley saying: "We almost couldn't produce enough to keep the appetite of our investors happy. More people wanted bonds than we could actually produce. That was our difficult task, was trying to produce enough" (Goda and Lysandrou, 2014, p. 314).

${ }^{9}$ In her model, Nikolaidi (2015) assumes the existence of three different categories of households: worker households-type I, worker households-type II, and rentier households.
} 
each single household's disposable income, and to determine the endogenous evolution of income (and wealth) inequality.

In each period, households define the desired consumption level according to their disposable income and a 'socially determined' term. On top of this, households can keep their savings either in the form of deposits, which pay no interests and are held for precautionary purposes only (e.g. to finance future consumption expenditures), or as IFs' shares. In the attempt of meeting their desired levels of consumption and portfolio choices, households can ask for a loan to commercial banks. Considerations on borrower's creditworthiness guide banking sector's decision on whether to grant the required loans to the household, and the determination of the household-specific interest rate.

CBs endogenously create money by extending loans to households and non-financial firms. The degree by which CBs create new loans depends on the assessment of borrowers' creditworthiness, as well as on prudential evaluations about their leverage (or capital requirements). In order to circumvent possible regulatory-imposed restrictions to further expansion of their business, CBs rely on securitization. In each period of our model, an endogenous share ' $z$ ' of the total loan stock is securitized and moved onto SPVs' balance sheet. We represent SPVs as a macro-aggregated sector, which performs the transformation of loans into securities. Such complex financial practice consists in collecting a share ' $\mathrm{z}$ ' of CBs-created loans to be used as 'primary commodities' for the production of collateralised debt obligations (CDOs), which are ultimately sold to IFs. IFs are financial intermediaries that collect funds by issuing shares sold to households. Collected funds are invested in financial markets by purchasing public bonds and CDOs. IFs buy government bonds as risk-free assets. CDOs produced by SPVs are meant to satisfy (rentier) households' appetite for higher but still relatively safe returns.

We capture the importance of conglomerated financial holdings in the US financial market by assuming that IFs - which can be thought as non-bank financial institutions - own the banking sector. Accordingly, CBs' profits are entirely passed, in the form of dividends, to IFs. Dividends from CBs, interests on CDOs and interests on government bonds constitute IFs' revenues.

On top of heterogenous households, the real side of the economy is completed by a macro-aggregated non-financial productive sector and by the government. Non-financial firms (NFFs) produce a homogeneous good, sold to households for consumption, to the government for public purchases, or to the firm sector itself for investment purposes. NFFs accumulate productive capital according to the degree of capacity utilization (i.e. the intensity with which they utilize the available capital stock), as well as their profitability. The implementation of investment projects is financed by NFFs' net profits and loans from CBs. NFFs hold deposits as a precautionary stance against unforeseen events (i.e. unexpected increases in the wage bill). Similarly to Cardaci and Saraceno (2016) and Cardaci (2018), we keep the non-financial productive side of the economy as simple as possible. We neglect to consider any structural change or innovation process. In line with the macro-perspective of our analysis, our model offers a different (although complementary) perspective on the relationship between finance, inequality and economic performance with respect to the long-run, say structural, analysis carried out by other AB models (Ciarli et al., 2012; Dosi et al., 2013; Fagiolo et al., 2017).

Last but not least, the government collects taxes from households and firms, and makes public expenditures. Any difference between public expenditures and tax revenues is covered by issuing bonds, which are bought by CBs and IFs. The determination of bonds' yields depends on the market interaction between the supply of bonds and the corresponding demand from IFs and CBs.

Given the macroeconomic structure described in Tables A.1 and A.2 (section A in the appendix), our AB-SFC model is based on a simple demand-driven macroeconomic dynamics. We do not assume any supply constraint to apply, so that production is carried out to satisfy aggregate demand. In this regard, the financial sector of the economy plays a crucial role since that CBs may or may not finance consumption decisions by heterogeneous households and investment decisions by NFFs. More specifically, the process of "financial engineering" (i.e. the production of structured financial products via securitised loans) we describe in this paper can play a fundamental role inasmuch it may allow CBs to extend more loans to indebted households, possibly giving rise to higher consumption expenditures. At the same time this may cause a perverse redistribution of income in favour of wealthy rentier households, and increase the risk of deep systemic financial and economic crises. ${ }^{10}$

\footnotetext{
${ }^{10}$ In the present model, CBs credit to the households sector is aimed at financing consumption expenditures or the
} 
The demand-driven dynamics that characterises our AB-SFC model takes place through the following sequence of events, which happens in each period of our simulations:

1. Households receive their wages from NFFs and pay their wage tax.

2. Financial flows take place. Interests on public bonds are paid by the government. Commercial banks collect interests on issued loans and keep the portion coming form non securitized loans. CBs finally transfer their profits to IFs in the form of dividends. The part of financial proceeds deriving from securitized loans is passed to IFs via SPVs.

3. IFs compute their revenues given by the interests paid on securitized loans (as 'packed' into CDOs) and interests on public bonds holding. Revenues from invested funds are subdivided among shareholders in the form of remuneration of IFs' shares.

4. Households compute their disposable income out of wages, tax payments and net financial payments, and define their desired levels of consumption, deposits and stock of shares. Households go to commercial banks and ask for loans in order to cover any possible gap between their portfolio and consumption decisions and own liquid resources, i.e. disposable income and stock of deposits.

5. Commercial banks decide whether to grant loans or not to households.

6. Households adjust consumptions and portfolio decisions according to credit availability. When loans are granted households meet their desired levels of consumptions and financial investments.

7. The government makes public expenditures. NFFs decide investments according to previous period capacity utilization and profitability.

8. Firms produce and sell goods in order to satisfy aggregate demand. Whenever net profits do not cover the cost of investment, firms borrow money form the banking sector. If net profits exceed the cost of investments, the remaining is stored in the form of extra deposits.

9. The government issues public bonds in order to cover any public deficit. This safe assets are sold on financial markets and bought by IFs and CBs.

10. Financial transactions are completed with the purchases of CDOs by IFs. IFs decide the amount of funds collected from (rentier) households to allocate on CDO according to the spread between interest rates on public bonds and effective returns on CDOs.

\section{Behavioral equations}

\subsection{Households}

We start the description of the equations composing our model from the households sector. Equations (1)-(2) describe how household-specific disposable income is determined.

$$
\begin{gathered}
y d_{i, t}=w_{i, t}-\operatorname{tax}_{i, t}^{w}+r s h_{i, t}-r_{i, t-1}^{h} \widetilde{L h_{i, t-1}} \\
\operatorname{tax}_{i, t}^{w}=\tau_{j}^{w} w_{i, t}\left\{\begin{array}{l}
\text { if } w_{i, t}<\hat{w}_{t} \Longrightarrow \operatorname{tax}^{w}=\tau_{1}^{w} * w_{i, t} \\
\text { if } w_{i, t} \geq \hat{w}_{t} \Longrightarrow \operatorname{tax}^{w}=\tau_{1}^{w} * \hat{w}+\tau_{2}^{w} *\left(w_{i, t}-\hat{w}_{t}\right)
\end{array}\right.
\end{gathered}
$$

The individual family unit and the time of the simulation are identified respectively by the subscript $i$ and $t$. In Equation (1), $y d_{i, t}$ stands for disposable income. $w_{i, t}$ is the exogenous gross wage each individual

accumulation of financial assets. We do not consider any housing sector. This is clearly a simplifying assumption and a limitation of the present model, which we nevertheless introduce to keep the model as simple as possible, as well as focused on its core topic, i.e. enquiring the co-evolution of income and wealth inequality and of modern financial systems. The introduction of the housing sector represents one of the next steps we want to take in future evolutions of the present work. 
household receives from NFFs at the beginning of each period. In this regard, we assume that the total wage bill $W_{t}$ is set exogenously as a given proportion $\lambda$ of the capital stock. ${ }^{11}$ The household-specific gross wage $w_{i, t}$ is then determined through a stochastic process that distributes the total wage bill over heterogeneous households according to a log-normal $(1, \theta)$ distribution. We assume that stochastic shocks can modify, to some extent, wage inequality even though they do not change the ranking of wages. The inclusion of stochastic shocks in the process of wage generation is meant to capture unforeseen events like unemployment that may hit some households and influence their disposable income.

Taxes $\operatorname{tax}^{w}$ levied on wages are modelled in a progressive fashion, as reported in Equation (2). The government charges two different tax rates, $\tau_{1}^{w}$ and $\tau_{2}^{w}$, with $\tau_{1}^{w}<\tau_{2}^{w}$. The former is charged on wages lower than the median wage rate $\hat{w}_{t}$, whilst $\tau_{2}^{w}$ applies to the part of wage exceeding $\hat{w}_{i, t}$.

The second component of disposable income $y d_{i, t}$ is given by net financial payments. In Equation (1), $r s h_{i, t}$ stands for the rent that each household may receive on its eventual holding of IFs' shares. Similarly, $r_{i, t-1}^{h} \widetilde{L h_{i, t-1}}$ represents 'effective' interest payments done by household $i$ to the banking system according to its own specific interest rate $r_{i, t-1}^{h}$ and its outstanding debt stock $L h_{i, t-1}$. This is the endogenous component of households' disposable income (and, hence, of income inequality). In an economic system in which households' debt represents a liability for the indebted units but also a source of income for the family units holding IFs' shares, households' financial outlays and entries are tightly connected and feed one another in a circular process. The remuneration of IFs' shares comes in part from returns on CDOs, which are in turn affected by the capacity of households to meet their financial commitments on securitised loans composing CDOs themselves. This is the essence of the endogenous redistribution process from debtors to rentiers, and the source of the ensuing rising inequality, that may take place in modern financialized economies through the mechanisms of securitization, and which is formally enquired in this model.

In our model, we solve the simultaneous determination of households' financial commitments and financial rents through a recursive process. At the beginning of each period, each individual household starts to set its own financial commitments out of its gross wage, once paid taxes to the government and once a minimum amount of resources $\left(\tilde{c_{t}}\right)$ has been put aside for subsistence consumption. Together with payments from households, CBs and IFs collect payments from other debtors - i.e. NFFs and the government - and distribute them to (rentier) households in proportion to their shares. The remuneration of shares will be taken as a 'pure' addition to disposable income available for consumption purposes and wealth accumulation by those household units which entirely set their pending financial payments in the first round of the 'payment process'. On the contrary, those households that may still have some arrears will use the above financial income in order to pay, at least in part, what is overdue. This triggers a new round of redistribution of financial rents among share holders. We assume such recursive process to come to an end when new financial income available to an individual household represents less than 10 percent of its remaining interest commitments. Given the complexity of this mechanism, we make the simplifying assumption that loans have infinite-time maturity. As a consequence, households will bear the financial obligation of complying with interest payments, but not to repay the principal. On top of this, households will default, at least partially, when they cannot meet their interest payments. Defaulting households will be excluded from next rounds of credit creation. Whilst this assumption keeps the model tractable, in does not change the rationale of the financial mechanisms at the centre of our analysis (see more on this below). ${ }^{12}$

Once disposable income is defined, households decide the desired levels of consumption and assets accumulation. As far as consumption is concerned, we follow the increasing empirical evidence about the importance of consumption habits and cultural-social trends, say 'keep up with the Joneses', in the definition of desired consumption (Marglin, 1984; Frank, 2005; Cynamon and Fazzari, 2008). Accordingly, in Equation (3), each individual household sets its desired consumption level $c_{i, t}^{*}$ on the basis of the propensity to consume out of disposable income $c_{y}$, and a 'socially determined' consumption norm captured by

\footnotetext{
${ }^{11}$ From a theoretical point of view, this assumption is consistent with a Leontief production function characterising the production process in the non-financial sector of the economy. Once again, for the sake of simplicity, in this model we do not consider technological change or innovation processes that modify the fixed combination of labour and capital in a Leontief-type production process.

${ }^{12}$ Consistently with this assumptions, non-performing loans (NFL) are here defined as granted loans on which households do not meet their due interest payments.
} 
the average consumption observed in the previous period $\bar{c}_{t-1}$, multiplied by the parameter $c_{n}$, which may be conceived as the strength of the social norm. In line with the recursive process described above, each individual household holds a sufficient amount of liquid resources to achieve subsistence consumption $\tilde{c_{t}}$, which is a share $c_{s u b}$ of last period average consumption.

Once established desired consumption, desired savings $s^{*}$ follows straightforwardly as the difference between disposable income and desired consumption (see Equation (4)).

$$
\begin{aligned}
& c_{i, t}^{*}=c_{y} y d_{i, t}+c_{n} \bar{c}_{t-1} \\
& s_{i, t}^{*}=y d_{i, t}-c_{i, t}^{*}
\end{aligned}
$$

Equations (5) and (7) represent households' desired portfolio choice. Equation (5) defines the desired stock of deposits $D_{i, t}^{*}$ each household wants to hold as a precautionary stance against unexpected changes in disposable income. This is a given share $\eta$ of previous-year stock of wealth $W H_{i, t-1}$. The ensuing desired variation in deposits is reported in Equation (6). Equation (7) formalises households' desired level of IFs' shares. Each family unit wants to increase or decrease its holding of IFs shares according to the difference between the observed return on shares $\left(r s h_{i, t-1}\right) /\left(S h_{i, t-1}\right)$ and the interest rate on bond, which represents the base rate of our economy.

In a way, Equation (7) simply says that, for each household, the return on shares needs to justify an eventual recourse to external financing for accumulating financial assets. Indeed, should $\left(r s h_{i, t-1}\right) /\left(S h_{i, t-1}\right)$ be lower than $i_{i, t-1}^{B},{ }^{13}$ it would make more sense to decumulate shares and repay back the outstanding debt. In Equation (7), parameter $\sigma$ stands for households' sensitiveness to the spread between the return on shares and the base rate. Consistently with Equation (7), Equation (8) computes the desired variation in the stock of IFs' shares held by household $i$. Equation (9), in turn, is the implicit desired budget constraint of each household. It defines the desired amount of new loans $\Delta L h_{i, t}^{*}$ that - given desired consumptions (savings) - household $i$ asks to CBs in order to implement the desired increase (decrease) in the stock of deposits and IFs shares.

$$
\begin{aligned}
D h_{i, t}^{*} & =\eta W H_{i, t-1} \\
\Delta D h_{i, t}^{*} & =D h^{*}-D h_{i, t-1} \\
S h_{i, t}^{*} & =S h_{i, t-1}\left[1+\sigma\left(\frac{r s h_{i, t-1}}{S h_{i, t-1}}-i_{i, t-1}^{B}\right)\right] \\
\Delta S h_{i, t}^{*} & =S h_{i, t}^{*}-S h_{i, t-1} \\
\Delta L h_{i, t}^{*} & =\Delta D h_{i, t}^{*}+\Delta S h_{i, t}^{*}-s_{i, t}^{*}
\end{aligned}
$$

Households' capability to realize their plans depends on CBs' willigness to accept loan applications. In our model, CBs assess the creditworthiness of each single household applying for a loan. In particular, CBs compare the household's 'desired' debt service ratio $m_{i, t}^{*}$ (see more about this below) to CBs' risk aversion and propensity to expand their business further. In our model, we capture this last point through the time-varying parameter $\psi_{t}$ (see more on this below). In the event that $m_{i, t}^{*}<\psi_{t}$, CBs will accept the loan application from household $i$, who will be allowed to carry out its desired consumption and accumulation decisions. This is formally stated in Equation (10):

$$
\text { if } m_{i, t}^{*}<\psi_{t} \Longrightarrow\left\{\begin{aligned}
\Delta L h_{i, t} & =\Delta L h_{i, t}^{*} \\
\Delta S h_{i, t} & =\Delta S h_{i, t}^{*} \\
\Delta D h_{i, t} & =\Delta D h_{i, t}^{*} \\
c_{i, t} & =c_{i, t}^{*}
\end{aligned}\right.
$$

In the event that $m_{i, t}^{*}>\psi_{t}$, CBs will reject household's application for bank's credit. For the sake of simplicity, we exclude the possibility for partial rationing at micro level (i.e. CBs will concede the full amount of the requested loan or nothing). Nonetheless, partial rationing can still emerge at macro level

\footnotetext{
${ }^{13}$ The interest rate on bond, $i_{i, t-1}^{B}$, plays the role of the base rate and proxies the potential cost of indebtedness.
} 
for the households sector as a whole. Households getting their loan denied, adjust their original plans. We assume credit-constrained households to follow a 'pecking-order' revision strategy. They first scale down the accumulation of IFs shares, and perhaps even liquidate part or all of them. Revision of desired deposits and, if necessary, reduction of the existing deposit stock comes next in order to maintain the desired consumption level. In the extreme case that disposable income and existing liquidity could not provide enough resources to cover for desired consumptions, household's consumption will reduce to the subsistence level $\tilde{c}$. The sequence of revisions in households' choices is formally described in the system of options below (Equation 11):

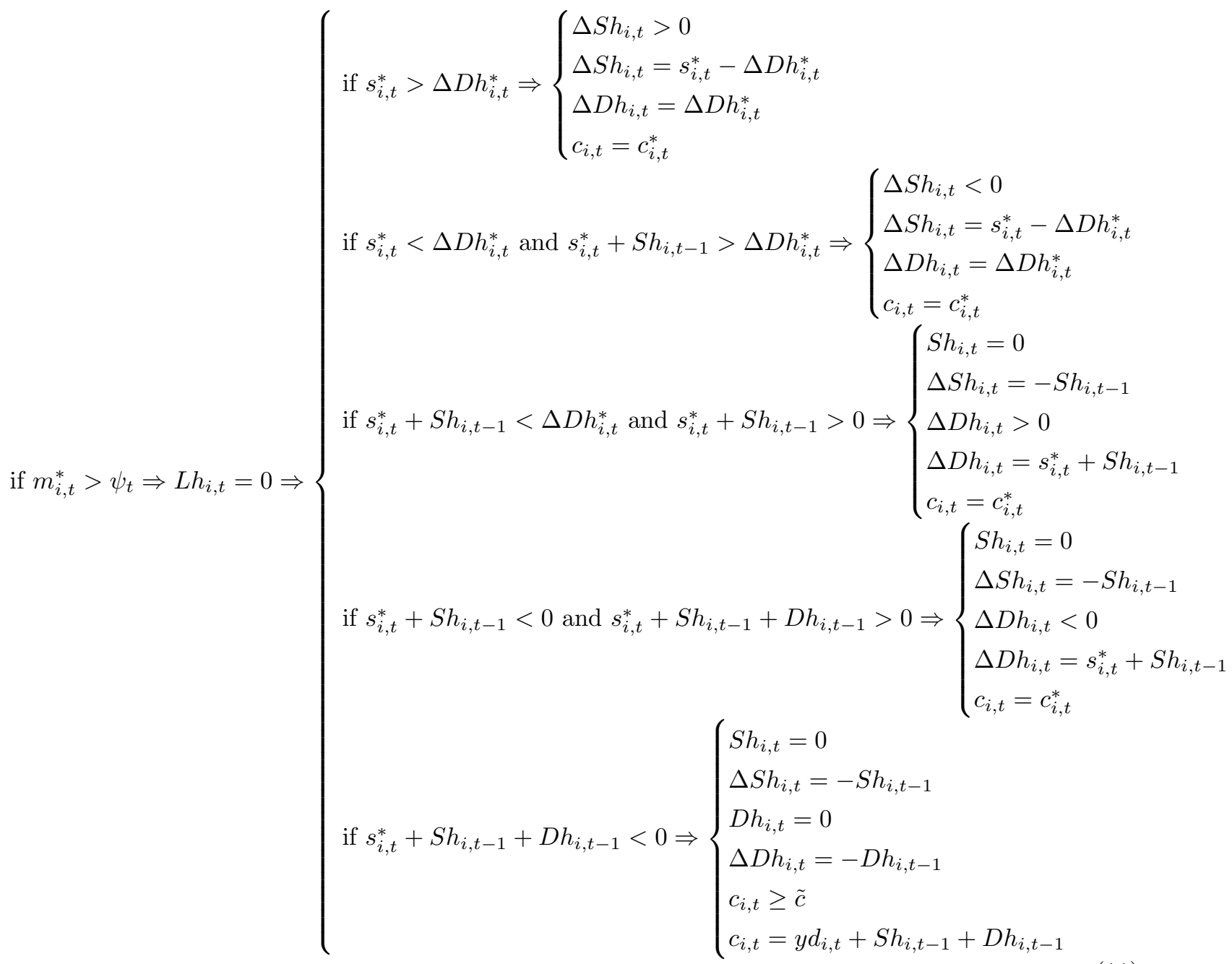

Wealthiest households may end up in the antithetical situation in which available and savings outstrip the resources needed to accumulate the desired level of deposits and shares. In this scenario, we assume that households will deleverage and pay back their loans. If the entire individual debt is repaid, the household will keep any extra saving in the form of extra shares. This last set of each individual 
household's allocation decision is modelled by Equation (12):

$$
\text { if } \Delta L h_{i, t}^{*}<0 \Rightarrow\left\{\begin{array}{l}
\text { if } L h_{i, t-1}>\Delta L h_{i, t}^{*} \Rightarrow\left\{\begin{array}{l}
L h_{i, t}=L h_{i, t-1}-\Delta L h_{i, t}^{*} \\
\Delta S h_{i, t}=\Delta S h_{i, t}^{*} \\
\Delta D h_{i, t}=\Delta D h_{i, t}^{*} \\
c_{i, t}=c_{i, t}^{*}
\end{array}\right. \\
\text { if } L h_{i, t-1} \leq \Delta L h_{i, t}^{*} \Rightarrow\left\{\begin{array}{l}
L h_{i, t}=0 \\
\Delta S h_{i, t}=\Delta S h_{i, t}^{*}+\left[L h_{i, t-1}-\Delta L h_{i, t}^{*}\right] \\
\Delta D h_{i, t}=\Delta D h_{i, t}^{*} \\
c_{i, t}=c_{i, t}^{*}
\end{array}\right.
\end{array}\right.
$$

\subsection{Commercial Banks}

CBs and SPVs are at the core of the securitzing system. They play a major role in shaping the behaviour of the economy through their decisions about credit rationing and the amount of loans securitized.

In our model, CBs create money by conceding loans to households and NFFs. As far as households' loans are concerned, CBs decide whether to provide each single household with the desired amount of credit (i.e. $\Delta L h^{*}$ ) on the basis of a two-step process. CBs will first assess the creditworthiness of each single potential borrower measured by the household-specific desired debt-service ratio (see Equation (13)), where $E\left[r_{i, t}^{h}\right]$ is the expected interest rate CBs would apply to the updated household's debt stock in the event of its application being successful. The expected interest rate $E\left[r_{i, t}^{h}\right]$ is defined in Equation (14). CBs set $E\left[r_{i, t}^{h}\right]$ through a mark-up on bonds' yields. In Equation (14), the previous-period interest rate on public bonds $i_{t-1}^{B}$ is the starting point for interest rate determination. The positive spread between $E\left[r_{i, t}^{h}\right]$ and $i_{t-1}^{B}$ is established as a function of a household-specific reference debt-service ratio, which is computed by applying the previous-period interest rate on bonds to the updated household's debt stock over disposable income. In Equation (14), ८ stands for a positive parameter revealing CBs' sensitiveness to households' reference debt-service ratio. Second, CBs will eventually grant the new loan depending on the household-specific desired debt-service ratio being lower than CBs' aversion to risk (see Equation (15)). We assume CBs' risk aversion to be represented by the time-varying parameter $\psi_{t}$ (see Equation $(16))$

$$
\begin{gathered}
m_{i, t}^{*}=E\left[r_{i, t}^{h}\right] \frac{L h_{i, t-1}+\Delta L h_{i, t}^{*}}{y d_{i, t}} \\
E\left[r_{i, t}^{h}\right]=i_{t-1}^{B}+\iota i_{t-1}^{B} \frac{L h_{i, t-1}+\Delta L h_{i, t}^{*}}{y d_{i, t}} \\
\text { if } m_{i, t}^{*}<\psi_{t} \text { and } \Delta L h_{i, t}=\Delta L h_{i, t}^{*} \text { then } r_{i, t}^{h}=E\left[r_{i, t}^{h}\right] \\
\left.\psi_{t}=\max \left(\bar{\psi}, \bar{\psi}+\omega\left(k_{B, t-1}-\bar{k}\right)\right)\right) \\
k_{B, t}=\frac{B_{B, t}}{\left[\left(1-z_{t}\right) L_{t}+B_{B, t}\right]}
\end{gathered}
$$

The value of $\psi_{t}$ is negatively influenced by CBs' levarage $\left(1 / k_{B}\right)$ - see Equation (17). In our model, CBs hold two different types of assets: risk-free public bonds $B_{B}$ and riskier loans conceded to households and NFFs, i.e. $L=\left(L_{h}+L_{f}\right)$. Consistently with standard banks regulation as internationally enshrined in the Basel accords, public bonds holding is ranked at the status of own capital (BIS, 2011). Accordingly, 
we take the ratio of CBs' government bonds over total CBs' assets, i.e. $k_{B}$, as an inverse measure of CBs' leverage. This is compared with a threshold leverage ratio $\bar{k}$ as given by standard CBs' regulatory capital requirements. The higher $k_{B}$, the lower CBs' leverage, and the more likely the concession of new loans. On the contrary, in the event that CBs' portfolio composition would be relatively skewed towards riskier loans, CBs will be more reluctant to grant new loans. In Equation (16), we weight the importance of portfolio composition and leverage over CBs' credit policy through parameter $\omega_{2}$, with $\omega_{2}>0$.

In the age of securitization and shadow banking, CBs can actively manage both the asset side of their balance sheets. Active asset management takes place through the securitization of a share $z$ of existing CBs-created loans. Botta et al. (2018) show that CBs can reduce their leverage by offloading part of their loans onto the balance sheet of SPV, thus creating room for a new round of loans creation. In this paper, we capture this fact by reporting the endogenous securitization share $z$ at the demonimator of Equation (15). The higher the demand for CDOs (see below), the higher the demand for securitized loans, and the more easily CBs can raise $z$, reduce their leverage (i.e. increase $k_{B}$ ) and ultimately 'create new space' for the generation of new assets.

As for loans to the non-financial productive sector, CBs follow the same procedure just described. Accordingly, Equation (18) defines the interest rate $\left(r_{t}^{f}\right)$ on loans to NFFs, $L f_{t-1}$ being the outstanding stock of NFFs' debt, $\Delta L f_{t}^{*}$ its desired increase, and $P f_{t}$ NFFs' net profits.

$$
r_{t}^{f}=i_{t-1}^{B}+\iota i_{t-1}^{B} \frac{L f_{t-1}+\Delta L f_{t}^{*}}{P f_{t}}
$$

CBs can ration credit given to the macro-aggregated non-financial productive sector on the basis of the comparison between NFFs' targeted debt-service ratio and CBs' risk-adversion parameter $\psi_{t}$. Given the macro-aggregated nature of the non-financial productive sector, credit rationing is partial. In the event that the targeted NFFs' debt-service ratio would exceed $\psi_{t}$, CBs will extend loans to NFFs up to the point in which the effective NFFs' debt-service ratio is equal to $\psi_{t}$.

Last but not least, CBs purchase of government bonds. For the sake of simplicity, in this paper we amalgamate primary and secondary markets for public bonds together. IFs will demand public bonds according to the optimal allocation of collected funds among available assets, i.e. public bonds and CDOs (see more on this below in the investment funds block). CBs, in turn, will buy the residual amount of available public bonds unsold on the market. In this regard, we describe the behaviour of CBs consistently with the allocation of public bonds among financial operators as it effectively take place in the US economy (Garbade and Ingber, 2005). In the US financial system, where a certain amount of public bonds is allocated, by default, to non-competitive bidders regardless of the interest rate bid they make in public bonds' auctions. Moreover, "primary dealers", i.e. CBs in our model, always take part to public bonds' auctions and are actually the main players in order to make the market for government securities liquid and allow it to work smoothly. In our model, the buffer and market-maker functions that primary dealers perform in the US financial system is formalised by CBs filling any possible gap between the supply of public bonds and IFs' demand. This said, bonds' yields are determined by market forces and depend on whether CBs will have to increase their relative share of public bonds holding (with respect to the previous period) in order to clear the market (see more on this below). On the one hand, a relatively low demand for bonds (at least with respect to the supply) from IFs will imply force CBs to increase their contribution to the market for public securities, so that public bonds' yileds will raise. On the other hand, a considerable demand for public bonds from IFs will cause a squeeze in the buffer role of CBs and lead to a reduction in the interest rate on public bond. Equation (19) formally expresses the buffer action carried out by CBs on the market for public bonds. Given the total supply of public bonds on financial markets $G D_{t}$ and the quantity of bonds IFs want to hold on their balance sheets, i.e. $B_{I F, t}$ (see more on this later), the remaining will be allocated to CBs.

$$
B_{B, t}=G D_{t}-B_{I F, t}
$$

The flow of revenues that CBs receive from the creation of loans and from bonds' holding (and consistently with the securitization of part of the created loans) are reported in Equations (20), (21), and 
(22) below. Equation (23) gives CBs' total profits, which are eventually transferred to IFs in the form of dividends.

$$
\begin{aligned}
R L_{B, t}^{h} t & =\sum_{i=1}^{N}\left(1-z_{t-1}\right)\left[r_{i, t-1}^{h} \widetilde{L h_{i, t-1}}\right] \\
R L_{B, t}^{f} & =\left(1-z_{t-1}\right)\left[r_{t-1}^{f} L f_{t-1}\right] \\
R B_{B, t} & =r_{t-1}^{b} B_{B, t-1} \\
\Pi_{B, t} & =R L_{B, t}^{h}+R L_{B, t}^{f}+R B_{B, t}
\end{aligned}
$$

\subsection{Special Purpose Vehicles}

Special purpose vehicles play an important role, although rather passive, in the process of securitization and creation of structured financial products (CDOs). Indeed, their balance sheets is where securitised loans are stored in order to enable CBs to further expand credit. SPVs package securitised loans together in order to create an apparently safer asset (i.e. CDOs) to the benefit of rentiers. Other way around, SPVs are the institutions allowing the financial system to give rise to the 'originate-and-distribute' practice replacing the 'originate-and-hold' practice that traditionally characterised the process of bank loans creation. The relevant function SPVs perform in our model is formalised by Equations (24), (25), and $(26)$ :

$$
\begin{array}{r}
z_{t} \sum_{i=1}^{N} L h_{i, t}+z_{t} L f_{t}=C D O_{i f, t} \\
z_{t}=\min \left(1, \frac{C D O_{I F}}{L_{t}}\right) \\
r_{t}^{c d o}=\frac{z_{t}\left[\left(\sum_{i=1}^{N} r_{i, t-1}^{h} L h_{i, t-1}\right)+r_{t-1}^{f} L f_{t-1}\right]}{C D O_{i f, t-1}}
\end{array}
$$

Equation (24) says that, in each period, the asset side of SPVs' balance sheets is made up of a portion $z_{t}$ of all the loans originally created by CBs. For the sake of simplicity, we assume that $z_{t}$ is homogeneous across loan categories, i.e. CBs securitise on demand an equal portion of all the loans created so far regardless of the (household-) specific level of risk characterising any single loan. The liability side of SPVs is represented by CDOs created by SPVs themselves, and purchased on financial markets by IFs. Equation (25) defines the extent of the securitization process with respect to the original lending activity performed by CBs. Given total supply as determined by the total amount of loans generated through time by the banking system, $z_{t}$ is endogenously determined by the demand for CDOs from IFs. In our economy, CDOs stand for the complex structured financial products so widely demanded by IFs and so aggressively produced by investment banks (SPVs in our model) before the outbreak of the last financial crisis. Securitised loans are the raw material provided by CBs and used by SPVs for the production of CDOs themselves. Accordingly, the higher the demand for CDOs, the higher the demand for loans to securitize, and the higher the proportion of existing loans entering the securitization process. In this sense, it is worth noting that a downsizing of SPVs, due to the break down of investors confidence in the degree of safety of CDOs, would imply a drop in the demand for CDOs and the dry-up of the securitization chain. CBs would not only be forced to reduce the extent by which they can securitize, but they will have to reload on their balance sheet some of the loans previously offloaded and reduce the activism and benevolent approach in the concession of new loans.

Equation (26) shows how financial revenues are distributed throughout the whole economic system thanks to securitization and the production of CDOs. Indeed, interests originally paid by indebted households and NFFs, eventually accrue to (rentier) households as financial income on their (indirect) holding, mediated by IFs, of CDOs. Equation (26) also says that the remunerativeness and attractiveness (as investment opportunities) of CDOs is closely related to (indebted) households' capability to meet their interest payments on outstanding debt. The lower effective interest payments $r_{i, t-1}^{h} \widetilde{L h_{i, t-1}}$ made 
by households on their own debt, and the higher the rate of defaulting households and non-performing loans, the lower the remunerativeness of issued CDOs with respect to their 'face value'. Accordingly, IFs will likely re-orient their portfolio towards less remunerative but safer (in particular during times of financial turmoil) assets, namely public bonds. In the end, the viability of the SB system - and of the assets it produces - relies on an unstable equilibrium between the creation of an increasing amount of financial liabilities/assets and the preservation of households' financial 'solvency'.

\subsection{Investment Funds}

The last component of the financial system of our model are Investment Funds (IFs). IFs act as financial intermediaries collecting funds from households and deploying them to purchase financial assets. The financial revenues of IFs' investment - i.e. interests on public bonds and remuneration of CDOs - are ultimately distributed to (rentier) households as remuneration of their shares holding. Equations (27) (31)describe how IFs allocate collected funds among the different possible deployments, and the ensuing streams of IFs' revenues and payments (to rentiers).

$$
\begin{aligned}
D_{I F, t} & =\sigma S H_{t} \\
q_{i f, t}^{b} & =q_{i f, t-1}^{b}\left(1-\beta\left[\left(r_{t}^{c d o}-i_{t}^{B}\right)-\left(r_{t-1}^{c d o}-i_{t-1}^{B}\right)\right]\right. \\
B_{I F, t}^{D} & =q_{i f, t}^{b} S H_{t}(1-\sigma) \\
C D O_{I F, t}^{D} & =S H_{t}(1-\sigma)-B_{I F, t} \\
C D O_{I F, t} & =\min \left(z_{t} L_{t}, C D O_{I F, t}^{D}\right)
\end{aligned}
$$

IFs always keep a relatively small share $\sigma$ of collected funds $S H_{t}$ in the form of banks' deposit (see Equation (27)) as precautionary stance providing IFs with the required liquidity in the event that rentiers would like to redeem some shares. Total IFs' resources available for financial investments on interestbearing assets therefore amount to $(1-\sigma) S H_{t}$. Equation (28) establishes the share of deployable resources $q_{i f, t}^{b}$ IFs allocate to the purchase of government bonds. We model such portfolio allocation decision by looking at the relative remunerativeness of government bonds with respect to CDOs. In particular, IFs increase the share of available funds devoted to the purchase of public bonds when the spread between CDOs and government bonds, i.e. $\left(r_{t}^{c d o}-i_{t}^{B}\right)$ is lower than the spread registered in the previous period i.e. $\left(r_{t-1}^{c d o}-i_{t-1}^{B}\right)$. Given the higher degree of risk associated to CDOs with respect to public bonds, a reduction of the spread between the former and the latter will induce IFs to allocate an increasing share of available funds to bonds holding. In Equation (28), $\beta$ reveals the sensitiveness of IFs' portfolio decisions to changes in the spread between available assets.

Consistently with Equations (27) and (28), Equation (29) defines the demand for public bonds from IFs, whilst Equation (30) gives IFs' demand for CDOs. Equation (31) finally shows that IFs' demand for CDO $\left(C D O_{I F, t}^{D}\right)$ cannot exceed the maximum amount of CDOs potentially producible by the securitizing system (given by the total amount of existing loans that can potentially be securitised). The markets for CDOs and bonds might occasionally be supply-constrained. May this occur, the excess demand will take the form of liquidity hence increasing the stock of IFs' deposits.

Financial investments by IFs give rise to a stream of financial revenues which constitute the total amount of resources that IFs will divert to rentier households as remuneration of their shares. On top of this, IFs also receive profits from CBs. We assume banks dividends to be held in the form of deposits by the IFs sector. In order to keep the intuition of the model as clear as possible, we make the simplifying assumption that IFs do not distribute banks' dividends to (rentier) households. We chose to do so to put as much emphasis as possible on the redistribution of income that takes place through interest payments on low-middle income households' debt on the one hand, and the remuneration of the CDOs implicitly held by rentier households (via IFs' shares) on the other hand. ${ }^{14}$ Equations (32) and (33) define the

\footnotetext{
${ }^{14}$ Indeed, including the distribution of financial profits to households would have either blurred away the role of securitization in determining the remunerativeness of CDOs, since the returns on all loans, both securitized and not securitized, would have ended up in the hands of rentiers. Alternatively it would have required the introduction of a further assets, namely equity, and this goes far beyond the current aim of this paper.
} 
revenues IFs get on CDOs and bonds holding, respectively. Equation (34) determines the total set of payables to rentiers. The remuneration (rentier) households eventually get from IFs' shares is expressed by Equation (35), and it is proportional to the amount of shares each individual household 'i' holds (i.e. $\left.s h_{i, t-1}\right)$ with respect to the total amount of shares issued by IFs, i.e. $S H_{t-1}$.

$$
\begin{aligned}
R C D O_{I F, t} & =r_{t-1}^{c d o} C D O \\
R B_{I F, t} & =r_{t-1}^{b} B_{I F, t-1} \\
R S H_{t} & =R C D O_{I F, t}+R B_{I F, t} \\
r s h_{i, t} & =R S H \frac{s h_{i, t-1}}{S H_{t-1}}
\end{aligned}
$$

\subsection{Non-financial Firms}

In this paper, we assume the NF sector to be a simple macro-aggregated sector producing a homogenous good used both for consumption and investment purposes. Production decisions by NFFs are demanddriven and satisfy the demand for consumption, investment, and public purchases. Equation (36) defines consumption expenditures as the sum of each individual household realised consumption. Equation (37), in turn, defines the demand for new capital goods. We assume that the demand for capital goods depends positively on previous-period firms' profitability. Following Badhuri and Marglin (1992), the profitability of the macro-aggregated non-financial productive sector is captured by the profit share $\pi_{t-1}=\left(\Pi_{F, t-1} / Y_{t-1}\right)$, with $\Pi_{F, t-1}$ as previous-period NFFs gross profits, and $Y_{t-1}$ as previous period Gross Domestic Product (GDP). NFFs' investment demand also responds positively to the observed (previous-period) rate of capacity utilization, i.e. $u_{t-1}=\left(Y_{t-1} / K_{t-1}\right)$. In Equation (37), $\gamma_{1}$ and $\gamma_{2}$ are positive parameters, $\gamma_{2}$ being the well-known Harrod-type accelerator. $Z_{t}$ is the 'animal spirits' component of the investment function (weighted by parameter $\gamma_{3}$ ), which behaves as the stochastic process described in Equation (38). Capital accumulation is described by Equation (39), with parameter $\delta$ as the depreciation rate of the existing capital stock. Given public purchases (to be explained in the government box), Equation (40) eventually defines GDP $Y_{t}$, whilst Equation (41) identifies NFFs' gross profits as the difference between revenues and the wage bill paid to workers.

$$
\begin{aligned}
C_{t} & =\sum_{i=1}^{N} c_{i, t} \\
I_{t} & =\gamma_{1} \frac{\Pi_{t-1}}{Y_{t-1}}+\gamma_{2} u_{t-1}+\gamma_{3} Z t \\
Z_{t} & =\gamma_{4} Z_{t-1}+U(0,0.1) \\
K_{t} & =(1-\delta) K_{t-1}+I \\
Y_{t} & =C_{t}+I_{t}+G_{t} \\
\Pi_{F, t} & =C_{t}+I_{t}+G_{t}-W_{t} \\
\pi_{t} & =\frac{\Pi_{F, t}}{Y_{t}}
\end{aligned}
$$

Consistently with what already stressed for IFs, we assume that NFFs do not distribute dividends. NFFs retain all their net operative profits $P_{F, t}$ once paid corporate taxes to the government and interest rates on outstanding loans to the banking system. This is formalised in Equation (43). In Equation (43), $\tau_{3}$ is the governmental tax rate levied on NFFs' gross profits (see Equation (44)) for the total amount of taxes paid by NFFs), whilst $R L^{f}$ stands for interest payments from NFFs towards the financial system. Equation (45) defines NFFs' financial payment commitments as given by the ruling interest rate $r_{f, t-1}^{l}$ on loans to NFFs and the outstanding NFFs' debt stock $L f_{t-1}$.

At any period, NFFs wants to hold a certain amount of liquid assets, i.e. CBs' deposits, in order to cover for unexpected events, say increases in the wage bill or maintenance costs of installed capital goods. NFFs set the desired amount of liquid assets as a positive proportion $\mu$ of the capital stock (see Equation (46). The ensuing change in NFFs' stock of deposits is reported in Equation (47). 


$$
\begin{aligned}
P f_{t} & =\left(1-\tau_{3}\right) \Pi_{F, t}-R L_{f, t} \\
T_{f, t} & =\tau_{3} \Pi_{F, t} \\
R L_{t}^{f} & =r_{f, t-1}^{l} L_{t-1}^{f} \\
D_{f, t} & =\eta K_{t} \\
\Delta D_{f, t} & =D f_{f, t}-D_{f, t-1} \\
\Delta L f_{t} & =I-P f_{t}+\Delta D_{f, t} \\
L f_{t} & =L f_{t-1}+\Delta L f_{t}
\end{aligned}
$$

Equation (48) defines the budget constraint of the whole NF productive sector. Equation (48) says that NFFs will fully retain net operative profits in order to finance the purchases of new capital goods as well as to increase their liquid assets. In the event available profits are not enough, NFFs will resort to credit from CBs. As already specified before, should credit rationing take place, NFFs will diminish deposits in order to finance and achieve their investment goals.

\subsection{Government}

When it comes to the government sector, Equations (50)-(52) define government's revenues (see Equation (50)) - given by taxes on households' wages and profits of NFFs - and government outlays. We decided to maintain the behaviour of the public sector as simple as possible, hence we assume that public purchases are set as a share $\xi$ of previous-period aggregate consumption $C_{t-1}$. On top of public purchases, the government makes interest payments on the outstanding amount of public debt. The costs of servicing public debt are reported in Equation (52).

$$
\begin{array}{r}
T_{t}=\tau_{3} \Pi_{F, t}+\sum_{i=1}^{N} \tau_{j}^{w} w_{i, t} \\
G_{t}=\xi C_{t-1} \\
G D S_{t}=r_{t-1}^{b} G D_{t-1}
\end{array}
$$

The difference between government outlays and tax revenues determines the public deficit in each period of our model (see Equation (53). Public deficit is in turn financed by issuing new government bonds (see Equation (54)).

$$
\begin{aligned}
\Delta G D_{t} & =G_{t}-T_{t}+G D S_{t} \\
G D_{t} & =G D_{t-1}+\Delta G D_{t}
\end{aligned}
$$

Public bonds issued on financial markets in previous periods plus the issuance of new government bonds determine the total supply of public securities. CBs and IFs purchase government bonds according to the different roles they perform in financial markets. In our model, yields on public bonds are determined by market mechanisms through the interaction between supply and demand in a recursive mechanism. First, the total supply of public bonds is defined (Equation (54)). Given the realised return on CDOs, as well as previous-period interest rate on public bonds, which constitutes the starting bid for the new round of government bonds' auctions, IFs declare which amount of public bonds they would like to hold in their portfolio. CBs come next. They make their bid for the remaining part of public bonds in excess with respect to the demand from IFs. In the event that CBs would have to increase their share of public bonds (over total supply) with respect to the previous period in order to clear the market, CBs will ask for higher yields. Alternatively, should their market-maker role go downsized given buoyant demand for bonds from IFs, CBs' bids on public bonds' yields will show a downward orientation. A second round of bids now starts, with IFs revising their own demand for bonds on the basis of what emerged in the last round and consistently with the observed behaviour of CBs. In each round bonds' 
yields will change depending on the parameter $\phi$ governing the speed of the adjustment process. Such a sequence of bids eventually comes to an end when further increases or reductions in yields on public bonds do not induce any further adjustment - namely the process hits the stopping condition related to the parameter $\bar{\epsilon}$ - in the demand from IFs and, as a consequence, in the buffer purchase from CBs. The complex mechanism behind the determination of government bonds' yields is formalised by Equation (55), where $r_{t}^{b}$ is a positive function of the share of public bonds (over total supply) CBs will eventually hold on their balance sheet.

$$
r_{t}^{b}=r_{t-1}^{b}\left[1+\alpha\left(\frac{B_{B, t}}{G D_{t}}-\frac{B_{B, t-1}}{G D_{t-1}}\right)\right]
$$

\section{Simulations}

Our hybrid AB-SFC model does not aim at reproducing the historical time series characterising a specific economy, or at accurately forecasting the future evolution of the variables at stake in a particular country. Our analysis is qualitative in its essence: we aim at analysing the co-evolution of finance and inequality in a stylised financialised economy from a theoretical point of view. For this reason, the initialisation of our simulations does not resemble the current state of any specific economy. It rather starts from a sort of 'virtual' economy with only an initial capital stock equal to 1. Accordingly, the value of the stock of all the other assets, namely banks' deposits and IFs' shares, is set to zero.

Albeit the qualitative nature of our analysis, the simulations are able to capture several stylised facts related to the US financial and credit markets, as well as to the harsh effects that dislocations in the financial sector of the economy may bear for the real side. Our model first reproduces a clear-cut credit cycle: the amount of credit issued by banks increases together with GDP, and it first stops and then decreases when a crisis occurs. Second, in our model the amount of non performing loans picks in correspondence to the crisis. This is consistent with what occurs in the real world and, in particular, it mirrors what happened in the US during the last crisis. Third, our model also reproduces the considerable decline in the share of securitised loans and the production of CDOs that just happened in the US since 2008. A forth interesting dynamics captured by the present model is flight to quality phenomena that may take place in times of financial distress. Indeed, similarly to what happens in the US in the wake of the sub-prime crisis, financial institutions relocate their portfolio towards safer public bonds and cause a considerable decline in bonds' yields even in presence of a widening public deficit and a soaring public debt. Last but not least, a fifth interesting property of our model is its capability to reproduce the negative correlation that exists in the data between the amount of non-performing loans and GDP growth rate. Consistently with the empirical evidence, in our model the increase in the amount of non-performing loans acts as a predictor of the end of the credit boom, an imminent financial crisis, and the likely start of an economic recession (see more on this below).

Given this initial setting, we run simulations over one thousand periods in order to let the 'structural properties' (i.e. the relationship between inequality and finance, as well as between finance and the real economy) of the economy develop and assume meaningful values. The list of parameters is reported in Table 1. In what follows, both statistics and plots are referred to the period 501-1000, so to get rid of transient dynamics. All simulations are checked for accounting consistency, in line with SFC literature (Godley and Lavoie, 2007; Caverzasi and Godin, 2014), both at individual and sectoral level.

The first computational experiment we perform includes two sets of multiple (Monte Carlo) simulations: (i) 100 simulations of the model without securitization (No Securitization), namely a scenario in which securitization does not take place (i.e. $z=0$ ) and the portfolio choice of IFs is therefore limited to either deposits or public bonds, and (ii) 100 simulations of the model with securitization (Securitization), where banks securitize a portion $z$ of their loans, varying with households' demand for financial assets. Results are reported in Table 2. In order to test whether the averages reported in the Table for the two scenarios are statistically different, we implemented a Two-Sample t-Test for Equal Means which always 


\begin{tabular}{|c|c|c|}
\hline Symbol & Description & Baseline \\
\hline $\mathrm{T}$ & Number of periods & 1000 \\
\hline $\mathrm{N}$ & Number of households & 1000 \\
\hline$\tau_{1}$ & Lower tax rate on income & 0.2 \\
\hline$\tau_{2}$ & Higher tax rate on income & 0.4 \\
\hline$\tau_{3}$ & Tax rate on profit & 0.5 \\
\hline$\gamma_{1}$ & Profit share weight (investment function) & 0.2 \\
\hline$\gamma_{2}$ & Capacity utilization weight (investment function) & 0.01 \\
\hline$\gamma_{3}$ & Animal spirit weight (investment function) & 0.1 \\
\hline$\gamma_{4}$ & Weight of the autoregressive component (investment function) & 0.9 \\
\hline$\eta$ & Precautionary deposits & 0.2 \\
\hline$\beta$ & Weight of CDO/Bond spread in IF portfolio allocation & 10 \\
\hline$\sigma$ & Sensitivity to return on share/base rate spread (household portfolio choice) & 1 \\
\hline$\phi$ & Speed of adjustment in public bonds' bids & 0.01 \\
\hline$\omega$ & Sensitivity to distance from desired share of bonds (banks credit rationing) & 0.3 \\
\hline$\iota$ & Sensitiveness to the debt service ratio (interest rate setting) & 1 \\
\hline$\epsilon$ & Tolerance in recursive processes (bonds and return on share determination) & 0.1 \\
\hline $\bar{k}$ & Desired share of bonds in banks' portfolio & 0.4 \\
\hline$c_{y}$ & Propensity to consume out of income & 0.8 \\
\hline$\delta$ & Capital depreciation rate & 0.03 \\
\hline$\lambda_{1}$ & Wage bill's determination out of capital & 0.15 \\
\hline$\xi$ & Public purchases' determination out of capital & 0.6 \\
\hline$\theta$ & Log-standard deviation (wage distribution) & 0.5 \\
\hline$c_{\text {sub }}$ & Subsistence consumption & 0.25 \\
\hline$c_{n}$ & 'Socially determined' consumption & 0.2 \\
\hline
\end{tabular}

Table 1: Parameters

rejected the null hypothesis except for the shares of GDP components and NPL means (more on this below).

The comparison between these two scenarios suggests that GDP growth appears to benefit from securitization. Public debt is considerably higher without securitization, whereas private debt, both as a stock over GDP and with respect to total net income (i.e. net wage plus the rents from IFs shares) is higher in the case of securitization. The Securitization scenario is also characterized by higher levels of both income and wealth inequality, and this seems to confirm the role played by securitization in favouring the rent-seeking activity of richer households. The higher inequality and private indebtedness linked with securitization determine higher financial fragility. It is worth noticing that while the means of Non Performing Loans are not statistically different, in the Securitization scenario the skewness is much higher. This fact is due to a sort of unstable Ponzi scheme the Securitization scenario allows for. Under securitization, the larger availability of credit to households allows some units to get even more indebted only to meet interest payments on their outstanding debt stock. One the one hand, this mechanism helps to lowering the average of non-performing loans and to keep it closer to what observed in the No Securitization scenario). On the other hand, however, such a Ponzi dynamics à la Minsky leads the debt to pile up until it becomes unsustainable and heavier defaults occurs, as testified by the much higher skewness.

In this regard, it is not by chance that the probability of a financial crisis (here arbitrary captured by a thresholds of unpaid interests on non performing loans above $5 \%$ of total interests) is more than three times higher when the financial system can rely on securitization. To sum up, while securitization appears to be beneficial for growth, as it makes easier for banks to provide loans to the private sectors, the boost in credit creation gives rise to higher inequality and more financial instability. Lower income households are indeed recurrently unable to service their debts and need to cut consumption below their desired level. A word of caution is in order. The absence of an asset which may loose value, as in a Fisherian debt-deflation crisis (Fisher, 1933), the aggregate CBs, SPVs, and IFs sectors, with the consequent lack 
of financial units defaulting, make the model resilient to crisis.

\begin{tabular}{|c|c|c|}
\hline & No Securitization & Securitization \\
\hline \multicolumn{3}{|l|}{ GDP growth } \\
\hline - mean & 0.0244 & 0.0249 \\
\hline - Standard Deviation & 0.0161 & 0.0156 \\
\hline - Skewness & -0.0653 & -0.0576 \\
\hline - Kurtosis & 2.0704 & 2.0553 \\
\hline GDP level* & 0.6123 & 1 \\
\hline \multicolumn{3}{|l|}{ GDP shares } \\
\hline - Consumption & 0.5456 & 0.5463 \\
\hline - Investment & 0.1270 & 0.1259 \\
\hline - Public Purchases & 0.3274 & 0.3278 \\
\hline Public Debt & 2.7408 & 1.8955 \\
\hline \multicolumn{3}{|l|}{ Gini Indexes } \\
\hline - Income & 0.2789 & 0.2908 \\
\hline - Wealth & 0.7188 & 0.7377 \\
\hline Loan Stock over GDP & 1.6438 & 1.7754 \\
\hline Debt to income ratio & 0.9508 & 0.9921 \\
\hline \multicolumn{3}{|l|}{ Non-Performing Loans** } \\
\hline - Mean & 0.0122 & 0.0118 \\
\hline - Standard Deviation & 0.0021 & 0.0027 \\
\hline - Skewness & 0.6035 & 0.9806 \\
\hline - Kurtosis & 4.4782 & 5.4731 \\
\hline - Crisis Probability*** & 0.0150 & 0.0490 \\
\hline Share of securitized loans & 0 & 0.2812 \\
\hline \multicolumn{3}{|c|}{$\begin{array}{l}\text { We implemented a Two-Sample t-Test for Equal Means which always rejected } \\
\text { the null hypothesis except for GDP shares and NPL means. } \\
{ }^{*} \text { GDP last period baseline }=1 \\
{ }^{* *} \text { Unpaid over due interests on loans } \\
{ }^{* * *} \text { Unpaid interest related to NPL above } 5 \% \text { of all interests }\end{array}$} \\
\hline
\end{tabular}

Table 2: Descriptive statistics comparing the baseline scenario ('No Securitization') with the 'Securitization' scenario.

Given these general features of our simulated economy, let's have a deeper look at the results of our simulations as to the joint evolution of the domestic financial sector and of inequality standards. We first look at the developments of the financial system with and without securitisation by analysing the the plots of a single simulation (which represents the typical dynamics already summarized above). Among other things, we pay particular attention to the capability of the financial sector to generate an increasing amount of loans thanks to the possibility to subsequently securitise part of them. We then check for the effect of securitisation and the diffusion of structured financial products on the evolution of both income and wealth inequality. We capture the evolution of inequality standards through the computation of the Gini index over gross income and gross wealth for the whole set of one thousand households composing our economy. We finally describe the main qualitative properties characterising the occurrence of endogenous crises as linked to unfolding dynamics in the financial sphere of the economy.

\subsection{Financial dynamics with and without securitization}

The four panels included in Figure 1 describe some relevant features of our simulated financial system. We pay attention to how financial dynamics changes according to the existence (or not) of securitisation. 
The functioning of the financial system without securitisation is represented by the blue dashed line. Financial dynamics associated to securitisation are represented by the orange solid line.
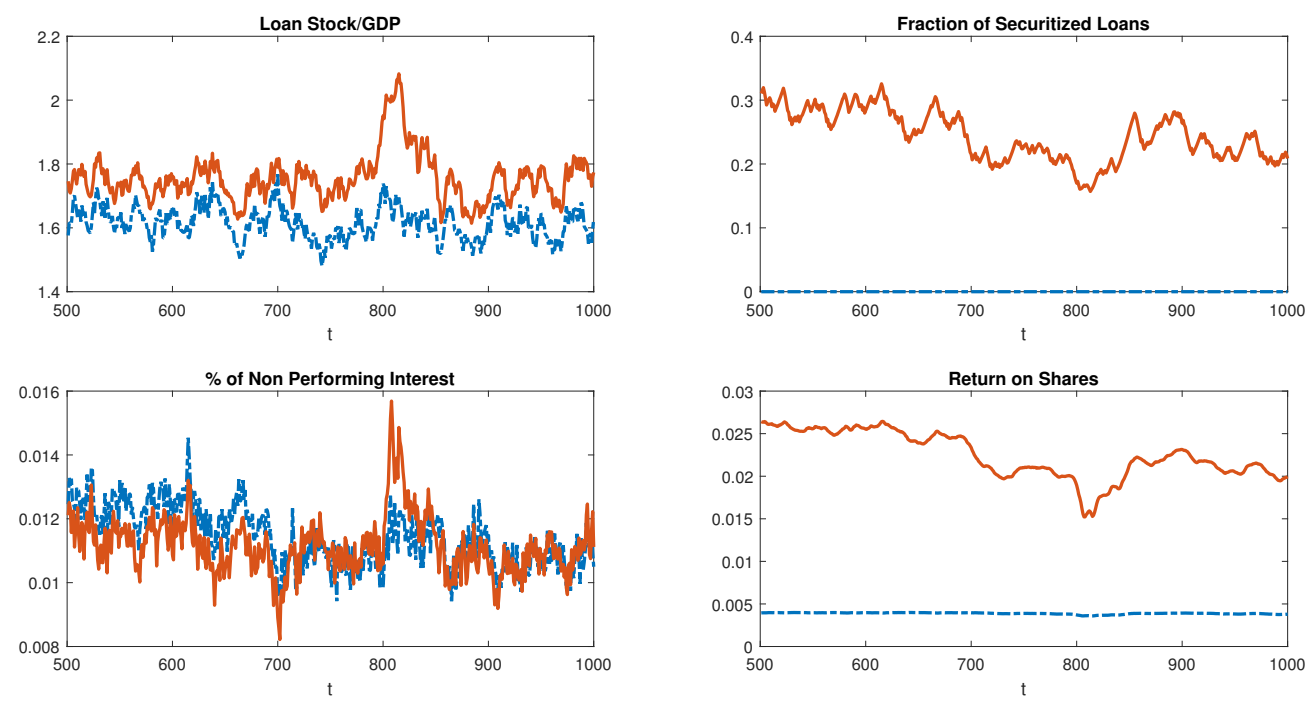

Figure 1: Descriptive Plots 1. The orange solid line is the scenario with securitization, the blue dashed line is without securitization (baseline scenario).

The upper-left panel in Figure 1 shows the total stock of loans (as a share of GDP) extended by CBs to the economy as a whole. It clearly shows the persistently higher amount of loans CBs can provide to the economy under securitisation. This is obviously due to the possibility CBs have to create new loans and then unburden their financial positions by putting part of them off their balance sheets. According to this panel, the creation of loans (as a share of GDP) by CBs increases by more than 10 percentage points when securitisation and 'originate-and-distribute' practices are allowed. Results portrayed in Figure 1 also show that such an upward drift is not constant. Indeed, our simulated economy experiences a credit boom around periods 750 and 800, when the stock of loans increases up to above 200 percent of GDP. This figure is roughly 40 percentage points more than in the baseline scenario excluding securitisation. Such an astonishing increase in the total stock of loans, and the ensuing rising degree of indebtedness of the economy as a whole, is then followed by an abrupt contraction. The credit boom eventually goes wrong and a quite standard credit boom-and-bust cycle takes place.

The evolution of credit inside the economy is obviously connected to the dynamics of the other financial variables reported in Figure 1. In the upper-right panel of Figure 1, we show the evolution of ' $z$ ', i.e. the total amount of securitised loans. It is important to keep in mind that in our model, ' $z$ ' is an endogenous variable, which depends on the demand for CDOs of which securitised loans are primary inputs. When securitisation is allowed, CBs generally put about 30 percent of existing loans out of their balance sheet. The bottom-right panel of Figure 1 shows how financial innovations such as the creation of structured financial products and the inclusion of CDOs in the portfolio of IFs considerably increased the remunerativeness of IFs shares with respect to the baseline scenario (in which only the interest on bonds contributes to the remuneration of shares). From our perspective, this is the clearest demonstration of how the financial innovations described in this model significantly contributed to the creation of a "rentier-friendly" economy.

The ratio of securitised loans is not constant. Interestingly, it tends to decrease when the crisis is approaching. The reason why this happens can be fully grasped by jointly analysing the bottom-left and bottom-right panel of Figure 1. The considerable increase of loans extended to the private sector helps the economy to grow faster. At the same time, however, it makes households and non-financial firms increasingly indebted. As the bottom-left panel reveals, a rise in the rate of non-performing loans takes 
place, as over-indebted households do not meet their interest payments. More in details, from period 700 on, the fraction of unpaid interest over due interests turns higher in the 'Securitisation' scenario than in the case without securitisation. It eventually skyrockets at time 800 . It is by no means incidental that this trend unfolds alongside with an increasing gap between the stock of loans created under securitisation (orange solid line) with respect to the baseline scenario (blue dashed line). The increase in non-performing loans in turn bears an obvious negative impact on the effective remuneration of CDOs and, consequently, IFs' shares. In the bottom-right panel, a reduction in the remuneration of shares appears from period 700. Whilst this reduces households' demand for IFs' shares, it also causes a drop in the amount of funds IFs allocate to CDOs (see more on this below), and hence in the demand for securitised loans. In the end, the increase in the amount of loans extended to the economy and a lower demand for securitised loans jointly cause a decrease in the degree of securitisation ' $z$ ' observed in our economy between periods 700 and 800 .

The ratio of securitised loans starts to increase again after the burst of the credit bubble when CBs considerably reduce the amount of loans extended to the economy. On top of this, tighter rationing ensures loans are given to a (relatively) restricted number of creditworthy counterparts. The ensuing increase in the effective remuneration of CDOs and IFs' shares brings back a high enough demand for CDOs and securitised loans, and contributes to rise ' $\mathrm{z}$ ' to pre-crisis-levels. Figure 2 provides some insights about the behaviour of the financial sector. The upper-left and the bottom-left panels in Figure 2 show the share of public bonds in IFs' portfolio and the dynamics of public bonds' yields, respectively. In particular, they show the above-mentioned 'flight to quality' that generally takes place when first rumours and symptoms of a financial crisis spread. In the upper-left panel, when the rise in non-performing loans reduces the remunerativeness of CDOs, IFs decide to divert collected funds towards risk-free government bonds. The market for CDOs shrinks and the share of public bonds in IFs portfolio increases. ${ }^{15}$ Such a rather dramatic (although temporary) switch in the investment decisions of IFs brings to a reduction in the yields on government bonds. The temporary reduction in government bonds' yields is considerably more pronounced in the securitisation scenario than in the baseline scenario. This might be taken as a first sign of the greater instability and propensity to give rise to episodes of 'flight to quality', which characterises modern financial systems.

The above impression that financial shocks can more easily take place in the context of a financial system with securitisation is confirmed by the upper-right and the bottom-right panels in Figure 2. The first one tells us that securitisation contributes to maintain CBs' leverage under control (and actually very close to the 'benchmark') even in presence of a considerably more active creation of loans. At the same time, when the credit boom unfolds (from period 700 to about 800), CBs' leverage (as captured by the inverse of the capital adequacy ratio $1 / \mathrm{k}$ ) skyrockets. This would not happen in the baseline scenario without securitisation, since that CBs would stop much earlier the expansion of credit given to the economy. In the end, securitisation reduces the aversion to risk of CBs, and allows them to reduce rationing and extend loans even to risky counterparts. This would have not happened had CBs been forced to keep all the created loans on their own balance sheets.

Interestingly, loose borrower screening by CBs during the credit boom is replaced by much tighter rationing (in absolute terms and with respect to the baseline) when the credit boom goes burst. After period 800, 25 percent of households are rationed (see bottom-right panel), and a sort of credit crunch takes place. This fact will obviously bring the economic system towards a recession (more on this below).

\subsection{Inequality}

Figures 3 and 4 help us to understand how the spread of modern financial practices, namely securitisation and the production of CDOs, do affect inequality standards. The left-panel in Figure 3 shows the evolution

\footnotetext{
${ }^{15}$ The upper-left panel in Figure 2 reports the share of funds IFs allocate to public bonds for the case with securitisation only. Indeed, in the baseline scenario without securitisation, IFs would allocate all the collected funds to public bonds given the absence of any alternative investment opportunity, namely CDOs. The share of IFs' resources allocated to bonds would then be persistently equal to 1 . The graphical representation of such a baseline scenario would 'visually' blur the 'flight to quality' phenomenon, which takes place when securitisation and CDOs are allowed, and signs of financial dislocation start to emerge. Therefore, we don not display the line in the baseline scenario.
} 

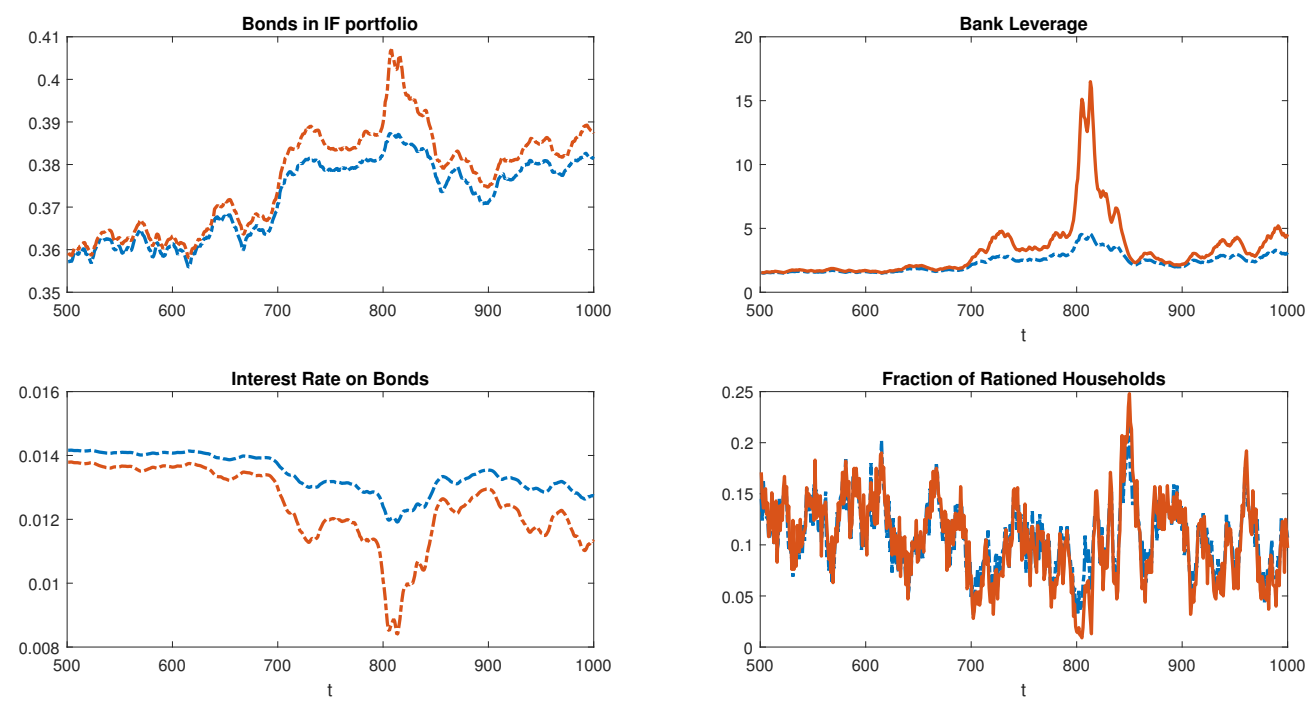

Figure 2: Descriptive Plots 2. The orange solid line is the scenario with securitization, the blue dashed line is without securitization (baseline scenario).

of the Gini index as computed on the distribution of gross income over one thousand households. The right-panel in Figure 3 shows the same inequality index now related to gross wealth. What emerges clearly from both panels is that income and wealth inequality reaches higher levels when modern financial practices develop with respect to a 'traditional' financial world without securitisation and CDOs.
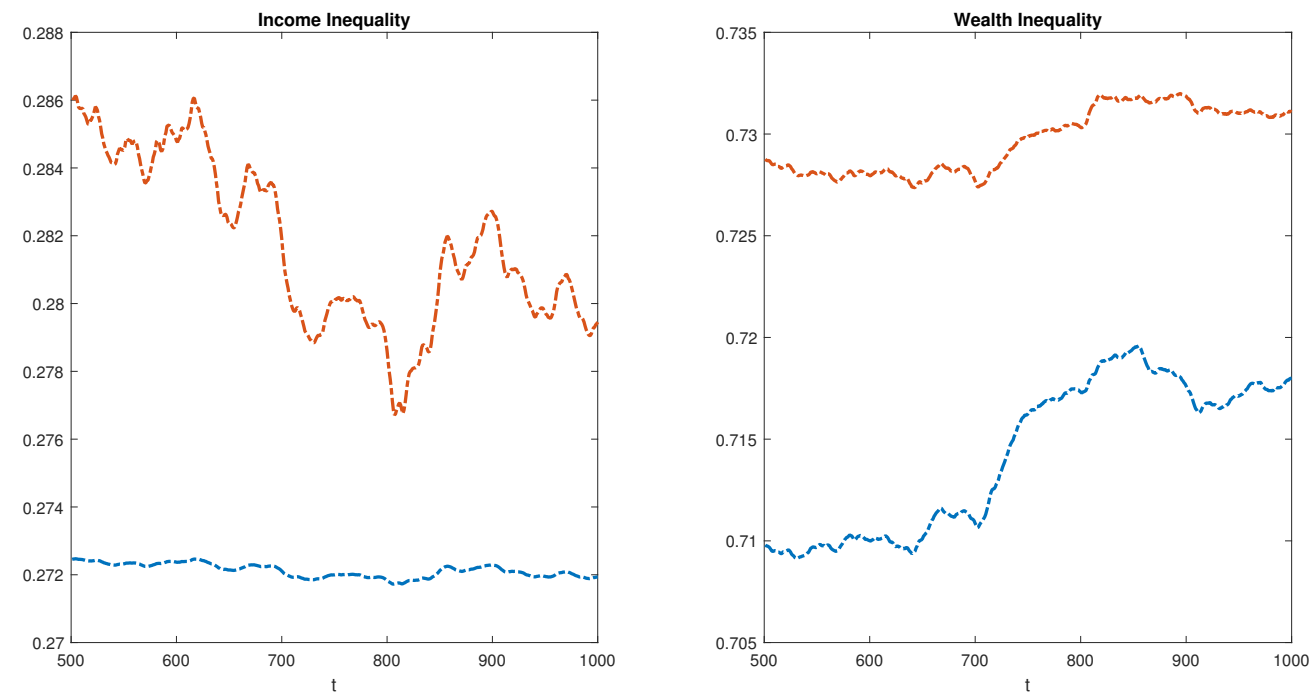

Figure 3: Inequality. The two graphs represent respectively the Gini index on income and wealth. The orange solid line is the scenario with securitization, the blue dashed line is without securitization (baseline scenario).

It is important to make some more points on the persistence of inequality. First, wealth inequality does not show any relevant sign of reduction, and it rather increases when a credit boom takes place, both with and without securitisation. This is due to the fact that whilst wealthy households increase their stock of wealth without recurring to loans (see more on this below), a larger number of middle and low-class households get indebted just to maintain consumption levels without accumulating any form of financial 
wealth. Income inequality shows a stable path when securitisation is out of the picture. This comes from the fact that the remuneration of financial investment from wealthy households exclusively depend on public bonds' yields rather than on more remunerative but far more volatile composite CDOs' yields. Income inequality reaches persistently higher but more unstable levels when securitisation and CDOs emerge. In particular, income inequality decreases when the symptoms of a financial crisis unfold. This is due to the fact that when credit booms develop, an increasing number of over-indebted households and firms do not set their interest payments, which in turn constitute the remuneration of rentier households' (indirect) investment in CDOs (via IFs' share).

The upper-left panel in Figure 3 shows that such a reduction in income inequality is purely transitory. Indeed, when financial markets restore their soundness after the outbreak of a full-fledge crisis, and only creditworthy borrowers are granted a loan, the distribution of 'exploitation rents' associated with the production of CDOs starts again together with a new rise in income inequality. Interestingly, this finding is consistent with the recent empirical evidence put forward by Piketty (2014) as to inequality dynamics in the aftermath of the most recent financial crisis. According to Piketty (2014), whilst income inequality has decreased during the crisis, it has quickly returned to even higher levels soon after. In the end, the outbreak of a full-blown financial shocks seem to emerge as temporary interruptions of much deeper and structural dynamics in the joint evolution of financial systems and inequality. More specifically, such a structural dynamics in inequality unfolds regardless the performance of the real economy, but mostly reflects the performance and functioning of financial markets.In a way, this might explain why inequality increased considerably in some advanced economic systems, namely the US and the UK, even in presence of fast-growing economies (at least in comparative terms with other developed countries) and with very low unemployment rates. Following Piketty (2014), our model shows how it is finace that increasingly plays a relevant role to explain the evolution of income and wealth inequality rather than GDP growth and unemployment.

Figure 4 provides some more information about wealth inequality, as emerging in the last period of simulation. Indeed, it shows the distribution of net wealth among all the one thousand family units composing our economy. Again, what emerges clearly is that net wealth is more polarised when we include securitisation and CDOs in our model than in the baseline scenario.

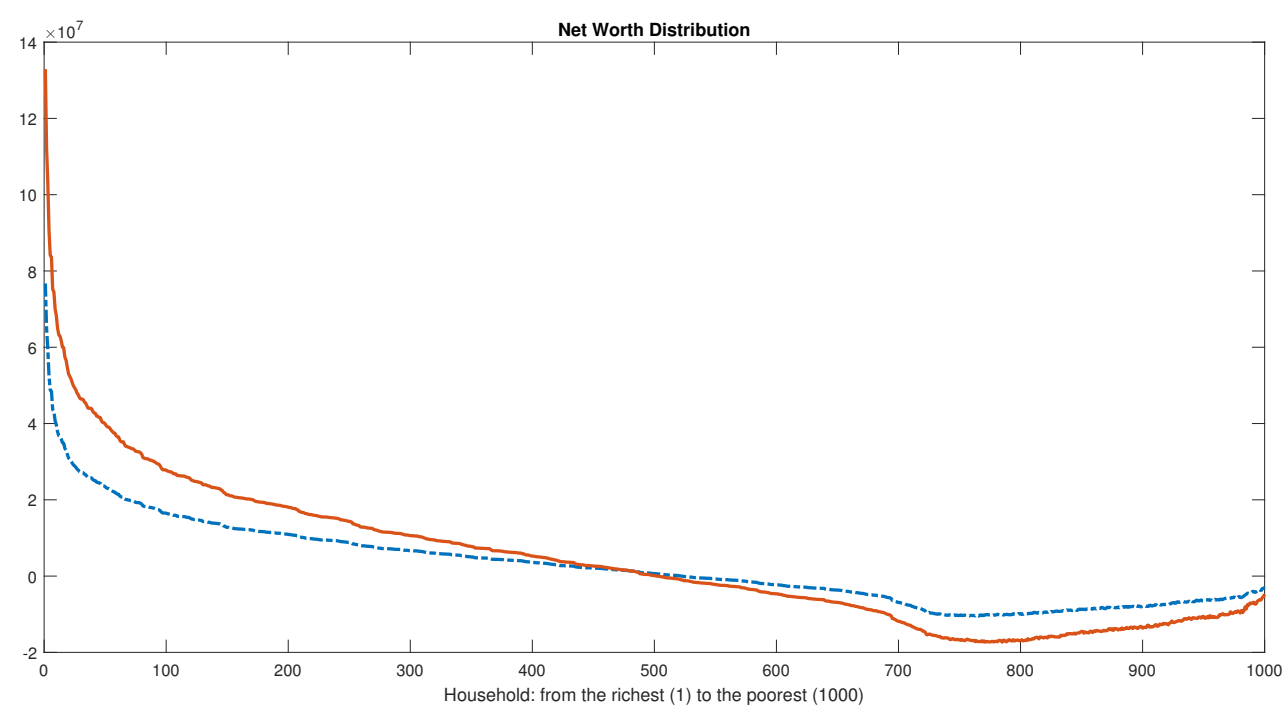

Figure 4: Net worth distribution. The graph represents the distribution of net wealth among households in the two main scenarios. The orange solid line is the scenario with securitisation, the blue dashed line is without securitisation (baseline scenario).

According to Figure 4, modern financial practices allow net wealth to become increasingly more concentrated in the top 10 percent households of the wealth distribution. On the contrary, the 50 percent 
households at the bottom of the distribution register a reduction of their net wealth. Some of them even enter in 'negative territory'. The increasing amount of loans they take just for satisfying consumption purposes force them to accumulate a negative net wealth. It is interesting to notice how credit rationing makes the net worth slightly increase at the bottom of the distribution. This is due to credit rationing. The poorest households, being more credit rationed, end up with a slightly higher net-worth compared to those receiving a little higher income.
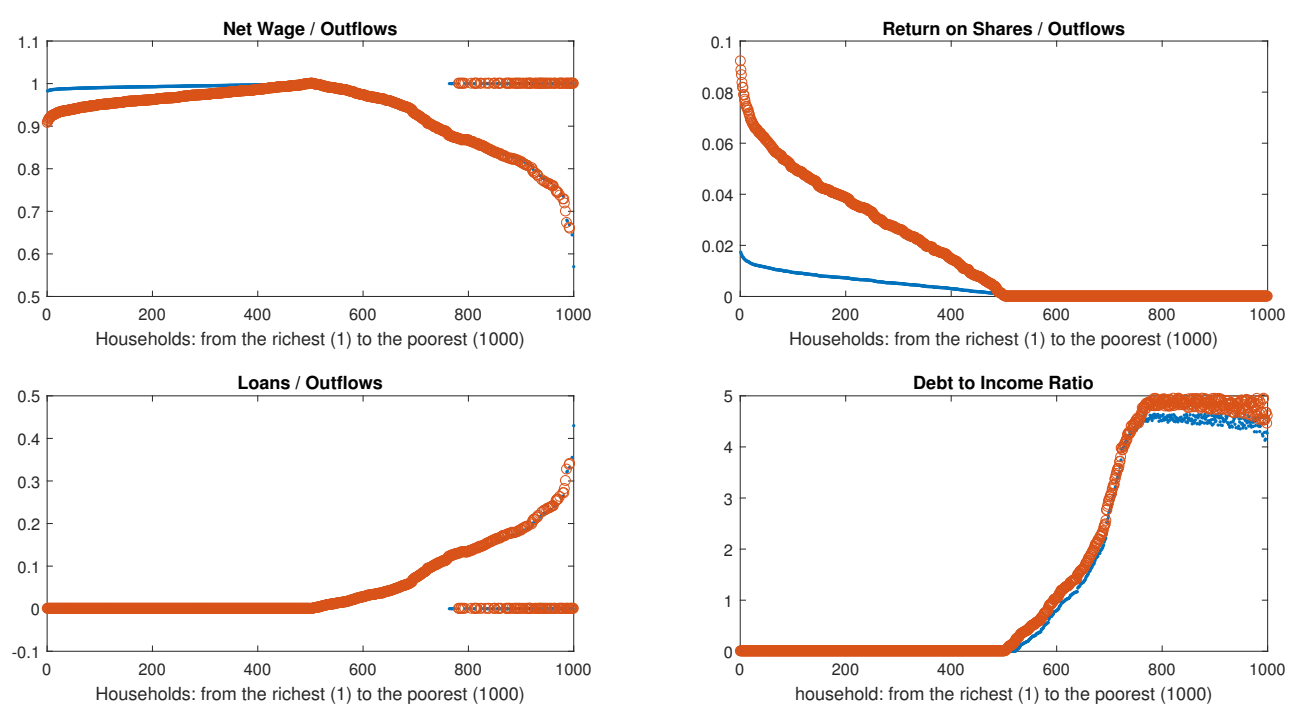

Figure 5: Flows Ratios. The two top graphs and the bottom-left graph show the weight of each monetary source on total outflows. The bottom-right graph represents the ratio between income and stock of debt. The blue dots represent the (baseline) scenario without securitisation and the red circles the scenario with securitisation. The four graphs show results from the last period of simulation. Households are ranked from the richest (left) to the poorest (right).

The financial flows that originate from such an increasingly unequal distribution of wealth are reported in Figure 5. The upper-left panel in Figure 5 shows that net wage covers for 90 percent of all current outlays (both for consumption or investment purposes) of top income households. The upper-right panel also shows that the production of CDOs and the higher remunerativeness of IFs' shares (with respect to the baseline scenario) allowed to increase the relevance of financial income in the budget of rentier households. Whilst financial income accounted for less than 2 percent (of households' outlays) in a world without securitisation, it has increased up to almost 10 percent after securitisation takes place and CDOs are produced. This obviously goes to the benefit of those rich households, which are wealthy enough to accumulate some interest-bearing financial asset. At least half family units are excluded from this process instead. Indeed, the bottom-right panel in Figure 5 shows that the debt-to-income ratio of the bottom 50 percent households increases when securitisation is introduced. The larger amount of financial commitments low and middle class households will have to deal with eventually constitute the source of the rise in financial income perceived by wealthy family units. Once again, we think this fact represents a clear example of new and deeper sources of 'exploitation rents' that may actually develop thanks to the pro-rich financial flows associated to securitisation and the proliferation of structured financial products.

\subsection{Financial crises}

In Sections 5.1, 5.2, and 5.3 we describe the structural relationship between some relevant financial variables and inequality standards that develop in our simulated economy over a long-run time horizon. In the present section we rather focus on the mechanisms behind the full-blown financial crisis that takes place around period 800 of our simulation scenario with securitisation. Figure 6 shows the co-evolution of CBs' leverage and non-performing loans. According to the figure, the former variable (CBs' leverage) seems to anticipate and drive the dynamics of the latter (non performing loans). Other way around, 
CBs start to extend an increasing amount of credit to the economy; a credit boom originates and CBs' leverage increases, with obvious implications for the (weaker) financial solidity of CBs themselves.

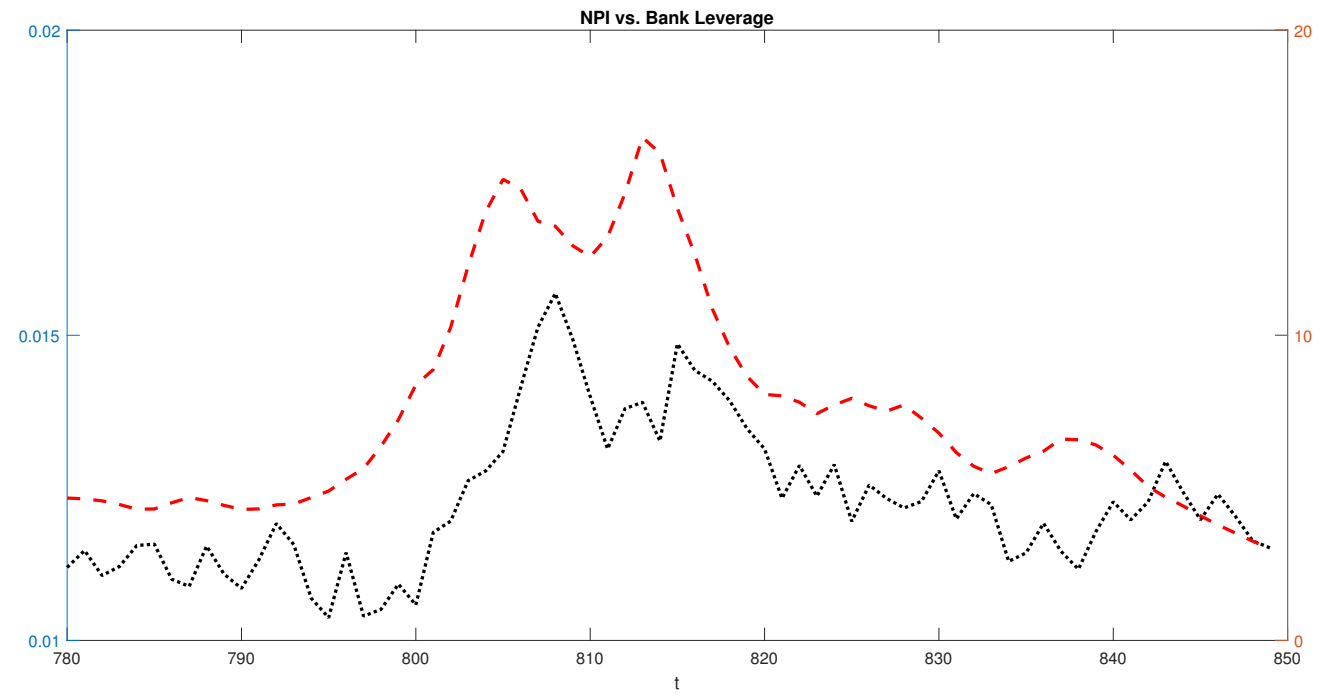

Figure 6: NPL vs Bank Leverage. The red dashed line represents banks leverage (right axis), the dotted black line represents the unpaid over due interests related to non-performing loans (left axis).

Non-performing loans follow with some lags. Increasingly indebted households and firms do not set all the expected interest payments, so that CBs' revenues and financial position deteriorate. CBs react to this event by adopting a stricter stance in the provision of new loans. Actually, access to credit becomes restricted to a much smaller number of creditworthy households and firms. Credit rationing and the burst of the credit boom take place, with the ensuing reduction in the amount of non-performing loans. Whilst the end of credit euphoria and CBs' deleveraging help CBs to restore some sort of financial soundness, the consequences for the dynamics of the real economy may be harsh. This is what emerges from Figure 6, which portrays the negative correlation between non-performing loans and the GDP growth rate. Figure 6 actually shows that soaring non-performing loans, here identified as delayed consequences of credit booms, are associated with reductions in economic activity and, eventually, economic slumps.

It is worth noting that the negative correlation between non-performing loans and real GDP growth ${ }^{16}$ (or, alternatively, the negative effect of a credit crunch over economic activity) is not a peculiar feature of the specific 'crisis event' we are currently describing. It actually emerges as a well-established statistical property of the full simulation over the entire time span we take into account. This is even more evident looking at Figure 8, which shows that, on top of the statistically significant negative correlation between current values on non-performing loans over GDP and real GDP growth, such a negative correlations gets even more negative for lagged values of non-performing loans up to four lags. In our model, whenever a credit boom initially gives rise to mounting financial fragility and to a rise in non-performing loans, it will soon or later trigger off a slowdown in economic activity if not a full-fledged economic crisis. Once again the similarity between model and real dynamics are remarkable. This can best be appreciated comparing Figure 8 with Figure 9. Both show the correlation between current values on non-performing loans over GDP and GDP growth, the former is based on the simulated data, while the latter on the actual US data. The resemblance is glaring.

The correlation between credit booms, increasing non-performing loans and, eventually, economic downturns, bring us back to the economic debate set out at the beginning of this work about to the most relevant factors behind crises. The story we describe in this last section is certainly consistent with the narrative put forward by Shularick and Taylor (2012) and Bordo and Meissner (2012), who

\footnotetext{
${ }^{16}$ In this model, real GDP is computed by removing from nominal GDP the dynamics of prices that naturally ensues by NFFs applying a mark-up over wage costs in order to ensure their own profitability.
} 


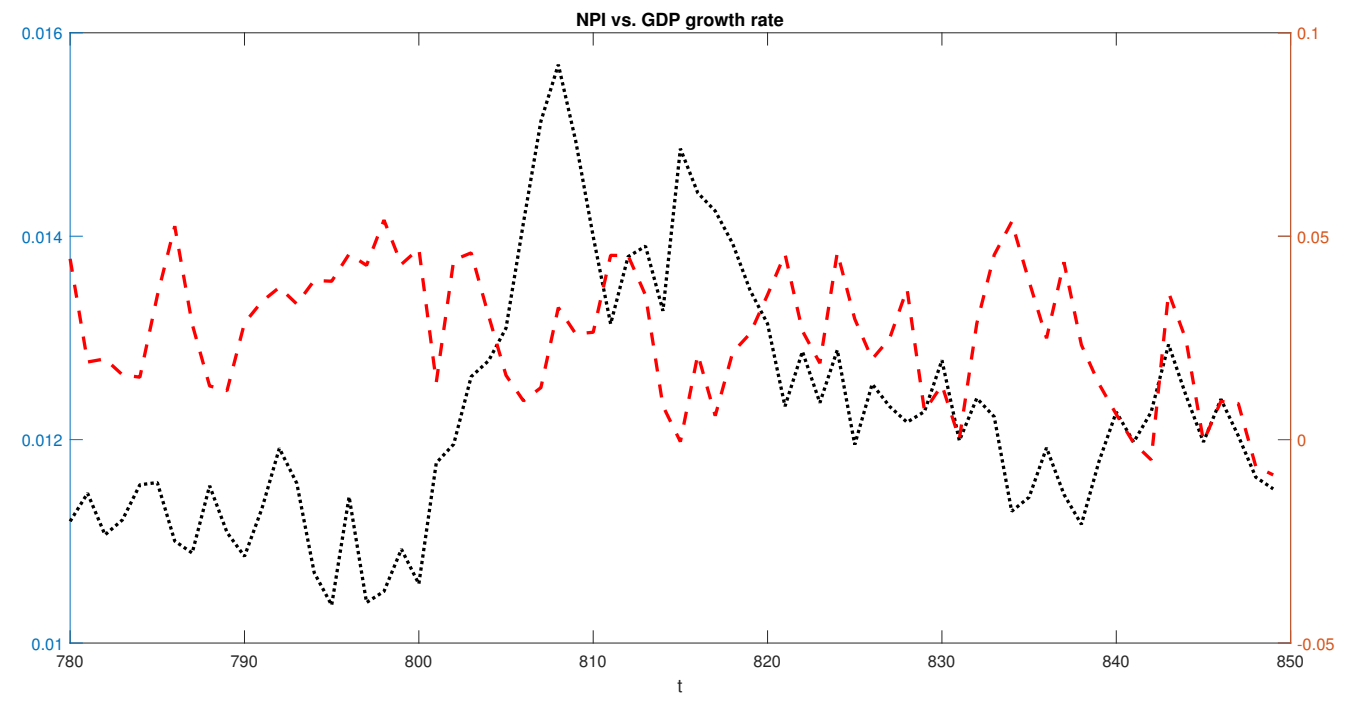

Figure 7: NPL vs GDP growth. The red dashed line represents the rate of growth of GDP (right axis), the dotted black line represents the unpaid over due interests related to non-performing loans (left axis).

identify credit booms as the most prominent causes and predictors of financial and economic crises. This fact notwithstanding, Shularick and Taylor (2012) and Bordo and Meissner (2012) neglect to analyse in details which are the economic and/or institutional factors, which enable financial institutions to frequently ignite and feed a credit boom. Shularick and Taylor (2012) and Bordo and Meissner (2012) rightly mention financial liberalisation and financial innovations as potential triggers of boom-and-bust cycles. But financial innovations are presented as exogenous events. In this model, we offer an alternative and perhaps more general view, in which financial innovations that can give rise to unstable dynamics are actually endogenous and tightly connected with the structural long-run forces governing the evolution of the economic system.

The 'credit-boom-gone bust' we describe in this section (with its connections with non-performing loans and economic growth) has been permitted by financial innovations such as the securitisation of existing loans and the production of structured financial products. At the very least, credit booms and unstable dynamics would have been far less acute in an economic system without securitisation. These financial innovations are in turn intrinsically connected with unfolding structural trends in the economy, namely rising income and wealth inequality. On the one hand, the production of CDOs is meant to provide IFs and, indirectly, wealthy households with those remunerative assets satisfying their appetite for high returns. On the other hand, the securitisation of existing loans, with the implicit transfer of debtors' interest payments from originating banks to rentiers, guarantees the supply of primary inputs for the production of CDOs themselves. This arm-length chain from inequality to economic dynamics passing by securitization and CDOs is once again synthetically demonstrated in Figure 9.

Figure 10 shows the negative correlation that clearly emerges between non-performing loans and the remunerativeness of IFs' shares at the time of the financial crisis in our simulation. A low level of non-performing loans ensures that indebted households and firms generally comply with their payment obligations, yields on CDOs are high as is the remunerativeness of IFs shares. But when the start of the credit boom eventually leads to an increase in the number of non-performing loans, the remunerativeness of CDOs and IFs shares decline. When the much lower remunerativeness of CDOs leads to a dry-up in the market for CDOs (see upper-left panel in Figure 2), the securitisation process enabling the credit boom comes to an end, and the boom inevitably goes bust. We already described the negative consequences this sequence of events may produce on real-side economic dynamics. What is relevant for the purpose of our analysis is that financial and economic crises emerge as the last outcome of the endogenous interplay between between financial innovations, financial dynamics, and economic inequality. In our simulated 


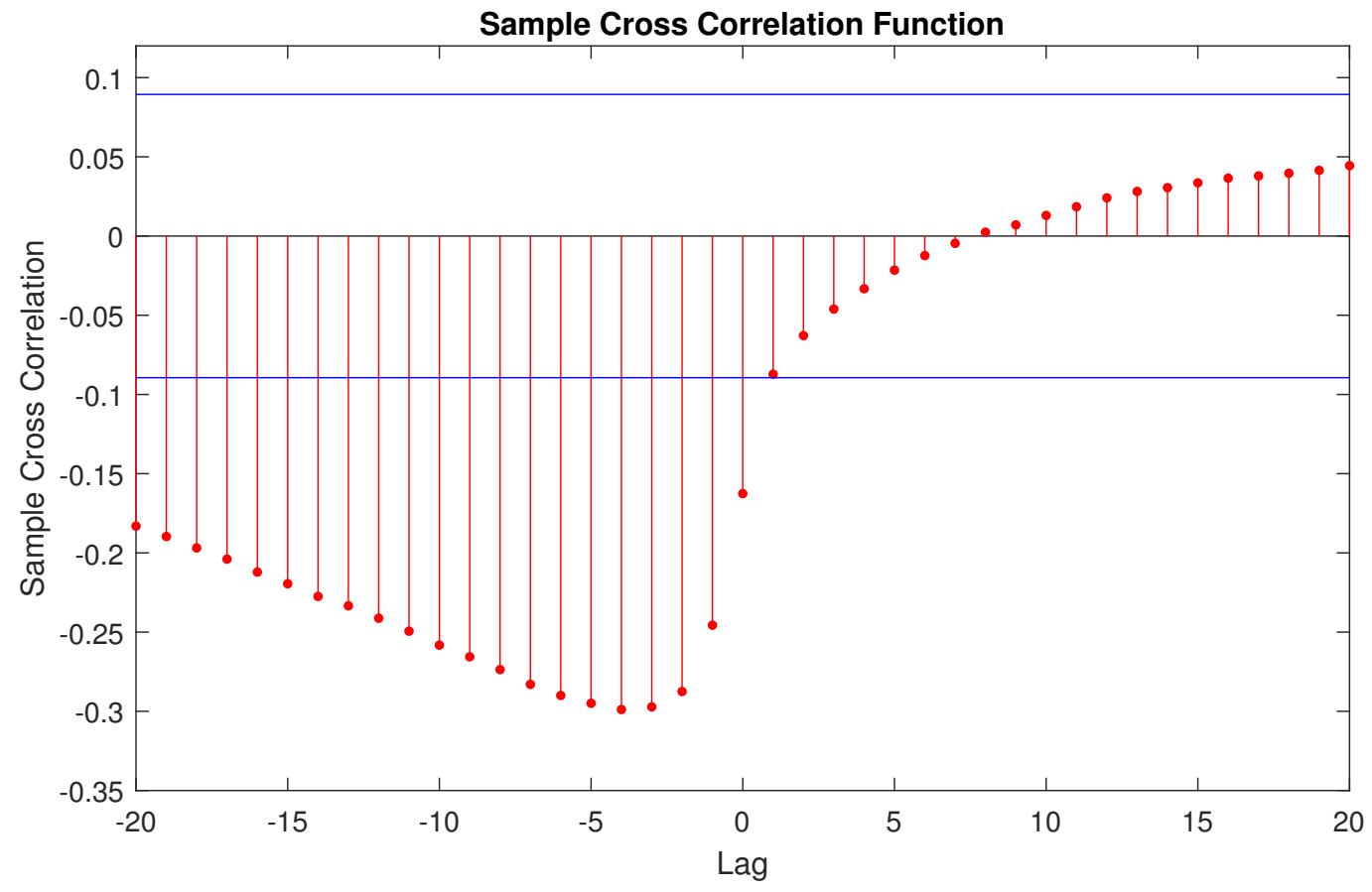

Figure 8: NPL and GDP growth cross correlation. Red bars represent the correlation between lagged values of nonperforming loans and current GDP growth, blue horizontal lines define confidence intervals.

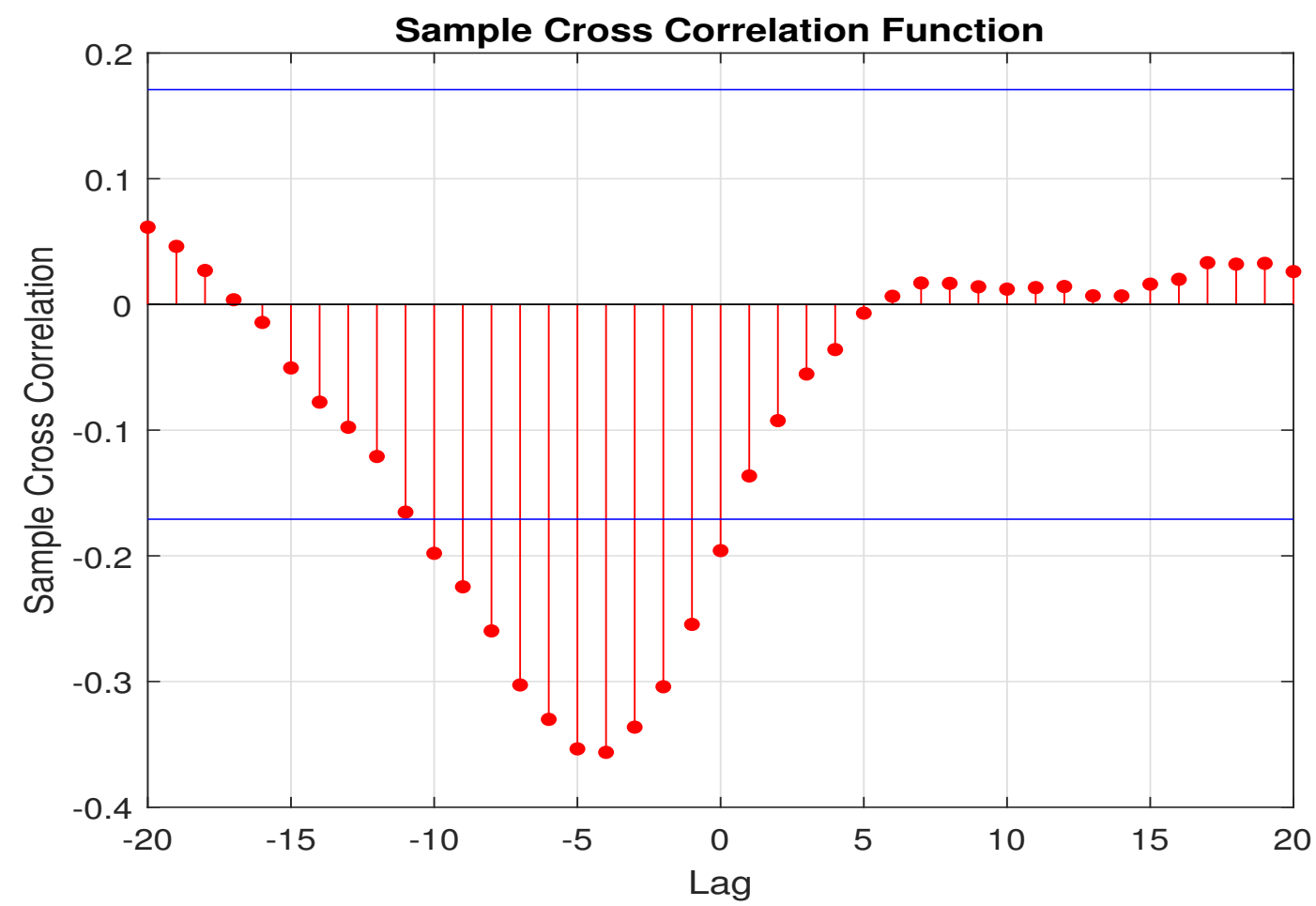

Figure 9: NPL and GDP growth cross correlation. Red bars represent the correlation between lagged values of nonperforming loans and current GDP growth, blue horizontal lines define confidence intervals. 


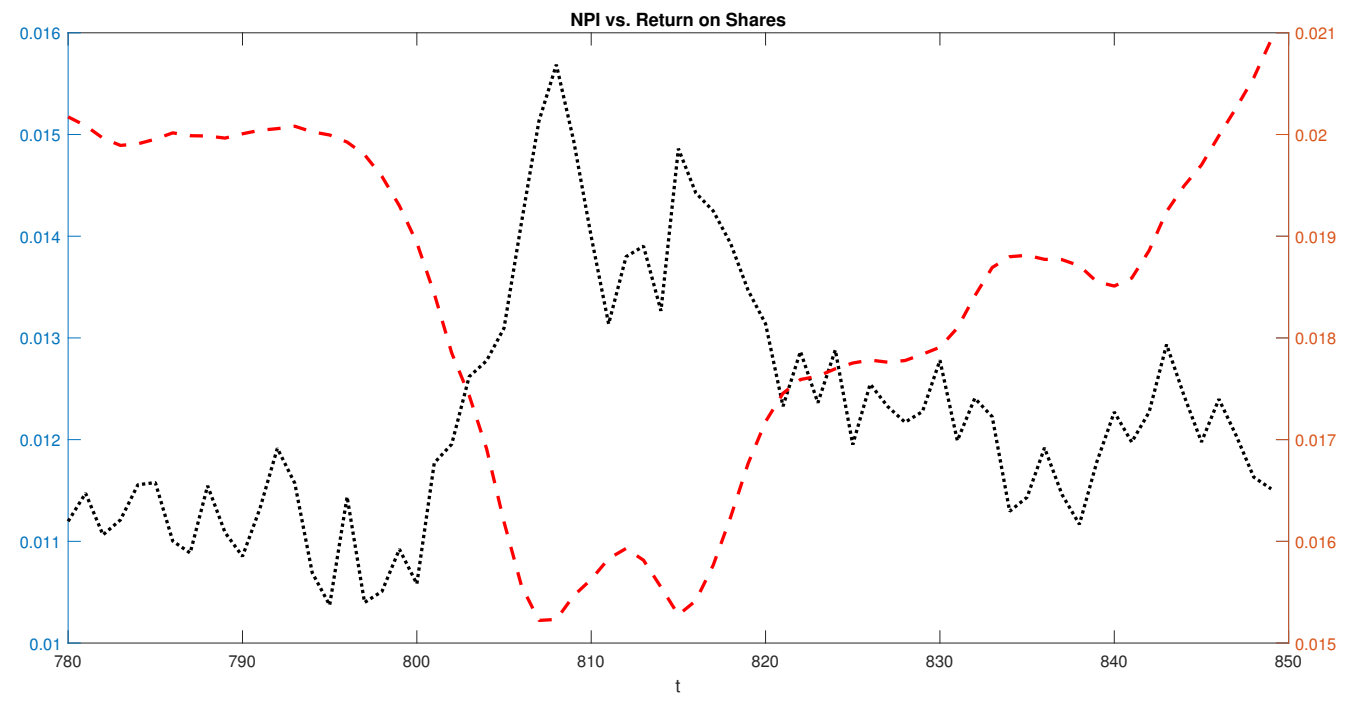

Figure 10: NPL vs Return on share. The red dashed line represents the return on shares (right axis), the dotted black line represents the unpaid over due interests related to non-performing loans (left axis).

economy, income inequality is all but neutral with respect to economic shocks.

As described in Section 1, our work focuses on a very specific and often overlooked determinant of inequality. Other economic and political aspects not portrayed in our model are equally or even more important in determining the level of inequality. In this section we describe the results of five computational experiments which involve the degree of tax progressiveness and wage inequality, applied to the Securitization scenario. In the first one we introduce a single tax rate for all households (Flat Tax). In particular, the level of the new tax rate $(0.252)$ is set so as to keep the fiscal balance almost unchanged, in order not to hamper the comparability of the descriptive statistics. The second experiment (Wage Inequality) regards a more unequal wage distribution. In particular, the second moment of the log-normal distribution of wages passes from 0.5 to 0.55 . In the more Progressive scenario the lower tax rate on income is decreased from 20 percent to 10 percent, while the higher is increased to 69 percent (once again the values were set so as to keep fiscal balances almost unchanged). A one percent tax rate is applied on households' wealth in the fourth experiment. Finally in the last experiments we introduced a ten percent tax rate on Investment Funds' profit. We perform additional batteries of Monte Carlo simulations by running 100 simulations for each new scenario and a robustness check by implementing a Two-Sample t-Test for Equal Means.]Policy Experiments

As described in Section 1, our work focuses on a very specific and often overlooked determinant of inequality. Other economic and political aspects not portrayed in our model are equally or even more important in determining the level of inequality. In this section we describe the results of five computational experiments which involve the degree of tax progressiveness and wage inequality, applied to the Securitization scenario. In the first one we introduce a single tax rate for all households (Flat Tax). In particular, the level of the new tax rate $(0.252)$ is set so as to keep the fiscal balance almost unchanged, in order not to hamper the comparability of the descriptive statistics. The second experiment (Wage Inequality) regards a more unequal wage distribution. In particular, the second moment of the log-normal distribution of wages passes from 0.5 to 0.55 . In the more Progressive scenario the lower tax rate on income is decreased from 20 percent to 10 percent, while the higher is increased to 69 percent (once again the values were set so as to keep fiscal balances almost unchanged). A one percent tax rate is applied on households' wealth in the fourth experiment. Finally in the last experiments we introduced a ten percent tax rate on Investment Funds' profit. We perform additional batteries of Monte Carlo simulations by running 100 simulations for each new scenario and a robustness check by implementing a 
Two-Sample t-Test for Equal Means. Descriptive statistics are presented in Table 3.

With respect to the Flat Tax scenario, table 3 shows the following results. While GDP growth does not pass our t-Test (i.e. the hypothesis for equal means is not rejected) the final level of GDP suggests that Flat-Tax is not beneficial for growth. Inequality increases as the two Gini indexes are higher and the rise is more acute in the case of wealth. Private debt, measured both with respect to GDP and net income, increases significantly. Lower tax on the ritch households, determine a higher demand for financial assets and therefore leads to more securitization and consequently easier credit issuance. This leads to a higher probability of a crisis to occur, albeit a lower mean of NPL. Indeed, the higher tax on low income households prevents some of them, those with lower income, to have access to credit. Nonetheless, the overall higher private indebtedness, together with a lower credit rationing for the richer households determine the higher crisis probability: a richer households can access to larger loans, his default therefore is more likely to lead to crisis.

The second scenario, Wage Inequality, is aimed at portraying the outcomes of a more unequal wage distribution combined with a financial system where securitization takes place (see again Table 3). The reasons for the increased wage inequality may be various, as a weakening of trade unions or new labor laws, and are not modelled in our paper. This scenario presents a level of GDP lower than Securitization and comparable to the Flat Tax. Public debt is in this case significantly lower and this comes at the expenses of a higher private debt. Inequality is higher, markedly on income. The main results of this scenario however pertains to financial fragility. Non performing loans are significantly higher and, more interestingly, the probability of crisis escalates to become seven time greater than in the Securitization scenario, which means almost thirty times higher than in the baseline scenario.

The More Progressive scenario presents a higher final level of GDP while inequality decreases, markedly on wealth. However, the more interesting result is the higher crisis probability, which comes rather unexpected in the face of a lower private indebtedness. The explanation lies in the Ponzi dynamics we have already described commenting Table 2. Lower income households, thanks to the tax cut, see their disposable income to increase. Accordingly, their debt service ratio decreases and they can eventually get easier access to new credit lines, given that CBs may likely evaluate low-income households' financial position more solid. Due to their low income, poorer households might anyway use new bank loans just to cover interest payments on their previous debt stock, hence cumulating debt until it becomes unsustainable.

In the the Wealth Tax scenario, the tax on households wealth determines a lower demand for financial assets, which in turn leads to less securitization. As a consequence, credit availability decreases, private indebtedness falls as crisis probability does together with it. GDP growth does not pass our t-Test. However, the final GDP level seems to suggest that this policy may not be beneficial for growth. This comes at the detriment of public finance as government debt rises. Both wealth and income inequality diminishes.

Finally, the Tax on Financial Profit scenario shows a very interesting dynamics in the relation between public and private debt. Indeed, what is a debt for the government is an asset for the private sector. The fall in public debt, determined by the tax on Investment Funds' profit, leads to a shortage of public bonds and to a reduction in bonds' yields. The financial sector responds to such a dynamics by diminishing its credit standards and issuing a larger amount of riskier loans in order to satisfy the demand for remunerative financial assets from households. This in turns leads to a significantly higher crisis probability. Such a dynamics recalls what happened in the sub-prime mortgage market.

The outcomes of these scenarios are even more interesting, if observed jointly and keeping in mind that all policies are here implemented on the scenario with securitization. The inequality-financial fragility nexus is not so straightforward, as among the different scenarios, a higher crisis probability is associated both with higher or lower levels of inequality, respectively for instance in the Wage Inequality and in the More Progressive scenario. What appears to be the main driver of financial fragility is the ease of access to credit, which is here linked to the demand for private debt-based financial assets (i.e. non government bonds). This suggests that the vituous nexus between more finance and lower inequality found by Levine (2005) (see Section 2) may require very specific and strict conditions to take place, and, in any case, it may come to the sacrifice of increased financial fragility (see the More Progressive scenario). Indeed, once obtained credit, poor households may very well use the inflow of money to buy goods or assets. However, unless purchased assets are income-generating, hence allowing for the debt to be repaid, the benefice will 
only be transitionary and the positive effect on wealth inequality illusional. The debt burden will soon become unsustainable and indebted poor households will default. This situation, if generalised, is bound to determine a full-fledged financial crisis. More than this, the ability of the financial sector to create assets based on private indebtedness coupled with a high demand for remunerative financial assets from the wealth owners, represents a dangerous combination and, in this perspective, public debt can have a stabilising effect since it supplies the market with safer financial assets. Accordingly, too much emphasis on fiscal austerity and on the need for a retrenchment of the public sector from performing relevant economic activities (here modelled through increases in taxes, but similar results could be obtained with a reduction in expenditures) can actually lead to a more unstable and financially fragile macroeconomic environment. In sum, easier access to credit, granted by securitisation, may very well be a self-defeating and destabilizing policy. In lights of these results, in Table 4 we combined different policies in order to obtain a desirable policy recipe. Based on the results of the policy experiments commented above, we implemented a policy mix composed of a reduced and more progressive fiscal load on households' incomes (more precisely, the lower tax rate on income is equal to $13 \%$, the higher tax rate is $55 \%$ ) and of the introduction of a tax on financial profits (with a tax rate equal to 10\%), so to keep unchanged the fiscal stance with respect to the baseline scenario with securitization. While the first policy is aimed at reducing inequality and boosting economic growth, the second policy allows to keep public finances on balance. In particular, the second intervention does not result in more private debt and securitization due to the parallel tax reduction on disposable income. Indeed, the t-test on equal means does not reject the null hypothesis of an equal average level of public debt on GDP in the two scenarios; overall, the null hypothesis is rejected only in the cases of GDP shares and the mean value of NPL. When the policy mix is implemented a higher average growth rate emerges from Monte Carlo simulations, giving rise to a final level of GDP which is almost 50\% higher than the corresponding baseline value. There is a reduction of both income and wealth inequality, which is related to a lower level of private indebtedness and a smaller weight of debt on households' income. This has a beneficial effect of macroeconomic performance, through boosting the consumption channel, via a redistribution from the rich to the middle-to-poor households, that eventually results in a stronger economic growth. It is worth noticing that the average level of NPL is similar and not statistically different, in the two scenarios, while the probability of financial crises is definitely reduced by the policy mix. All in all, the proposed policy is able to both boost economic growth and make the system less crisis-prone, by redistributing resources and promoting financial stability.

\section{Conclusions}

In this paper we analyse the interaction between finance and inequality. Most of the existing literature on this topic tries to assess how the former may affect the latter or vice versa. Nevertheless, it does not offer a comprehensive overview in which inequality standards and the development of modern financial systems co-evolve, feed back one into the other, and jointly shape the short- and long-run dynamics of an economy. With this work, we aim at filling this gap. For this purpose, we present a hybrid AB-SFC model featuring an economy composed by one thousand heterogeneous household units. We run a battery of Montecarlo simulations over a time horizons of one thousand periods through which we can infer how finance and inequality evolve and concur to determine the emerging structural properties of our simulated economy. Three points are worth noting as to the results of our simulations.

First, in a world allowing for the securitisation of Commercial Banks' loans, income and wealth inequality constitutes the in-depth sources for the demand of remunerative structured financial products (by wealthy households) and the ensuing securitisation of existing liabilities (of indebted middle and low class households). These modern financial practices in turn exacerbate income and wealth inequality with respect to a more traditional 'originate-and-hold' financial system without securitisation.

Second, the perverse interaction between rising inequality and and over-expanding financial system increases the probability of financial and economic crises. In our model, we verify that the concentration 


\begin{tabular}{|c|c|c|c|c|c|c|}
\hline & $\begin{array}{c}\text { Securiti- } \\
\text { zation }\end{array}$ & $\begin{array}{l}\text { Flat } \\
\text { Tax }\end{array}$ & $\begin{array}{c}\text { Wage } \\
\text { Inequality }\end{array}$ & $\begin{array}{c}\text { More } \\
\text { Progressive }\end{array}$ & $\begin{array}{c}\text { Wealth } \\
\text { Tax }\end{array}$ & $\begin{array}{c}\text { Tax on } \\
\text { Fin. Profits }\end{array}$ \\
\hline \multicolumn{7}{|l|}{ GDP growth } \\
\hline - mean & 0.0249 & 0.0248 & 0.0248 & 0.0251 & 0.0247 & 0.0250 \\
\hline - Standard Deviation & 0.0156 & 0.0158 & 0.0158 & 0.0153 & 0.0158 & 0.0156 \\
\hline - Skewness & -0.0576 & -0.0551 & -0.0570 & -0.0501 & -0.0559 & -0.0562 \\
\hline - Kurtosis & 2.0553 & 2.0778 & 2.0742 & 2.0265 & 2.0598 & 2.0726 \\
\hline GDP level* & 1 & 0.8766 & 0.8721 & 1.2048 & 0.8276 & 1.0552 \\
\hline \multicolumn{7}{|l|}{ GDP shares } \\
\hline - Consumption & 0.5463 & 0.5462 & 0.5462 & 0.5466 & 0.5460 & 0.5464 \\
\hline - Investment & 0.1259 & 0.1261 & 0.1262 & 0.1255 & 0.1264 & 0.1257 \\
\hline - Public Purchases & 0.3278 & 0.3277 & 0.3277 & 0.3279 & 0.3276 & 0.3279 \\
\hline Public Debt & 1.8955 & 1.8580 & 1.5575 & 1.8854 & 2.2840 & 1.2497 \\
\hline \multicolumn{7}{|l|}{ Gini Indexes } \\
\hline - Income & 0.2908 & 0.2935 & 0.3169 & 0.2853 & 0.2871 & 0.2891 \\
\hline - Wealth & 0.7377 & 0.7659 & 0.7526 & 0.6311 & 0.7302 & 0.7398 \\
\hline Loan Stock over GDP & 1.7754 & 1.8455 & 1.8374 & 1.6665 & 1.7005 & 1.8719 \\
\hline Debt to income ratio & 0.9921 & 1.0917 & 1.0211 & 0.8166 & 0.9746 & 0.9946 \\
\hline \multicolumn{7}{|l|}{ Non-Performing Loans } \\
\hline - Mean & 0.0118 & 0.0100 & 0.0189 & 0.0164 & 0.0122 & 0.0121 \\
\hline - Standard Deviation & 0.0027 & 0.0023 & 0.0050 & 0.0039 & 0.0024 & 0.0048 \\
\hline - Skewness & 0.9806 & 1.0663 & 1.5675 & 1.0589 & 0.6757 & 2.2762 \\
\hline - Kurtosis & 5.4731 & 5.8279 & 8.0132 & 6.0293 & 4.6854 & 11.8615 \\
\hline - Crisis Probability* & 0.0490 & 0.0530 & 0.3510 & 0.1200 & 0.0310 & 0.2590 \\
\hline Share of securitized loans & 0.2812 & 0.3061 & 0.2923 & 0.2364 & 0.2099 & 0.2596 \\
\hline \multicolumn{6}{|c|}{ * GDP last period 'Securitization' $=1$} & \\
\hline $\begin{array}{l}\text { Two-Sample t-Test for } \\
\text {-Flat Tax: for GDP growt } \\
\text {-Wage Inequality: for GD } \\
\text {-Wage Inequality: for GD } \\
\text {-Wealth Tax: for GDP Gr } \\
\text { - Tax on Fin. Profits: for } \\
\text { is not rejected }\end{array}$ & $\begin{array}{l}\text { Equal Mea } \\
\text { GDP share } \\
\text { growth, GD } \\
\text { Growth, GI } \\
\text { wth, GDP s } \\
\text { DP Growth }\end{array}$ & $\begin{array}{l}\text { is Result } \\
\text { P shares t Pub } \\
\text { P shares } \\
\text { ares and } \\
\text { GDP sha }\end{array}$ & $\begin{array}{l}\text { c Debt the nu } \\
\text { e null hypothe } \\
\text { ad Public Deb } \\
\text { PL the null hy } \\
\text { s, Ginis, Debt }\end{array}$ & $\begin{array}{l}\text { hypothesis is n } \\
\text { is not rejectec } \\
\text { the null hypoth } \\
\text { othesis is not } r \\
\text { o Income and } \mathrm{r}\end{array}$ & $\begin{array}{l}\text { rejected } \\
\text { is is not } r \\
\text { ected } \\
\text { L the nul }\end{array}$ & hypothesis \\
\hline
\end{tabular}

Table 3: Descriptive Statistics comparing the 'Securitization' scenario with five different scenarios: 'Flat Tax', 'Wage Inequality', 'Wealth Tax', 'Tax on Financial Profits'.

of wealth and income in the hands of a few rises the demand for remunerative financial assets (Investment Funds' shares and Collateralised Debt Obligations), which then spurs the securitisation of existing assets and allows CBs' to extend more loans to the economy. Whilst GDP growth may temporarily benefit from this, credit booms more likely unfold and eventually bust, giving rise to recessions. The absence of an asset which may loose value, the aggregate CBs, SPVs, and IFs sectors, with the consequent lack of financial units defaulting, make the model resilient to crisis. Feature developments of the model will relax this characteristics in order to better assess the impact of extend crisis and the role of financial speculation.

Third, we run two different computational experiments in order to see the effects of the introduction of a flat tax regime and of a more unequal distribution of wages on the performance of our simulated economy. In both cases, we find that income and wealth inequality increases. More importantly, we find that in both the experiments average GDP growth declines, its volatility increases, and the probability of crisis rises, in the second experiment (higher wage inequality) more than in the former (flat tax). Easier 


\begin{tabular}{|l|c|c|}
\hline \hline & Securitization & Policy Mix \\
\hline GDP growth & 0.0249 & 0.0253 \\
- mean & 0.0156 & 0.0152 \\
- Standard Deviation & -0.0576 & -0.0519 \\
- Skewness & 2.0553 & 2.0402 \\
- Kurtosis & 1 & 1.4859 \\
\hline GDP level* & \\
\hline GDP shares & 0.5463 & 0.5469 \\
- Consumption & 0.1259 & 0.1250 \\
- Investment & 0.3278 & 0.3281 \\
- Public Purchases & 1.8955 & 1.9006 \\
\hline Public Debt & & \\
\hline Gini Indexes & 0.2908 & 0.2880 \\
- Income & 0.7377 & 0.6893 \\
- Wealth & 1.7754 & 1.7195 \\
\hline Loan Stock over GDP & 0.9921 & 0.8850 \\
\hline Debt to income ratio & & \\
\hline Non-Performing Loans** & 0.0118 & 0.0138 \\
- Mean & 0.0027 & 0.0028 \\
- Standard Deviation & 0.9806 & 0.8213 \\
- Skewness & 5.4731 & 4.4541 \\
- Kurtosis & 0.0490 & 0.0210 \\
- Crisis Probability*** & 0.2812 & \\
\hline Share of securitized loans & & \\
\hline \hline We implemented a Two-Sample t-Test for Equal Means which always rejected \\
the null hypothesis except for GDP shares and NPL means. \\
* GDP last period baseline & \\
** Unpaid over due interests on loans & \\
*** Unpaid interest related to NPL above 5\% of all interests \\
\hline \hline
\end{tabular}

Table 4: Descriptive statistics comparing the baseline scenario ('No Securitization') with the 'Securitization' scenario.

access to credit, detached from a proper redistribution of income, appears to be a self-defeating and destabilizing policy.

All in all, the results of our simulations tend to reject the promises of 'trickle-down economics'. Unregulated (modern) finance, a better taxation for the rich, and/or a more throat-cut system (read higher wage inequality) do not improve economic dynamics, make economic systems more unstable and crisis-prone, and exacerbate the unequal distribution of resources. 


\section{A Accounting Matrices}

\begin{tabular}{|l|c|c|c|c|c|c|c|}
\hline & Households & Banks & SPV & IF & Firms & Gov & Total \\
\hline Deposits & $+D_{H}$ & $-D$ & $+D_{S P V}$ & $+D_{I F}$ & $+D_{F}$ & & 0 \\
Capital & & & & & $+K$ & & $+K$ \\
Shares & $+S h$ & & & $-S h$ & & & 0 \\
Bonds & & $+B_{B}$ & & $+B_{I F}$ & & $-B$ & 0 \\
Loans & $-L_{H}$ & $+(1-z) L$ & $+z L$ & & $-L_{F}$ & & 0 \\
Derivatives & & & $-C D O$ & $+C D O$ & & & 0 \\
\hline
\end{tabular}

Table A.1: Aggregate Balance Sheet (Initial Situation)

\begin{tabular}{|c|c|c|c|c|c|c|c|c|c|c|c|}
\hline & \multirow[t]{2}{*}{ Households } & \multicolumn{2}{|c|}{ Banks } & \multicolumn{2}{|c|}{ SPV } & \multicolumn{2}{|c|}{ IF } & \multicolumn{2}{|c|}{ Firms } & \multirow[t]{2}{*}{ Govt. } & \multirow[t]{2}{*}{$\Sigma$} \\
\hline & & $\mathrm{CA}$ & KA & $\mathrm{CA}$ & $\mathrm{KA}$ & $\mathrm{CA}$ & KA & $\mathrm{CA}$ & KA & & \\
\hline Consumption & $-C$ & 0 & 0 & 0 & 0 & 0 & 0 & $+C$ & 0 & 0 & 0 \\
\hline Publ. Exp. & 0 & 0 & 0 & 0 & 0 & 0 & 0 & $+G$ & 0 & $-G$ & 0 \\
\hline Investment & 0 & 0 & 0 & 0 & 0 & 0 & 0 & $+I$ & $-I$ & 0 & 0 \\
\hline Wages & $+W$ & 0 & 0 & 0 & 0 & 0 & 0 & $-W$ & 0 & & 0 \\
\hline${ }_{-}{ }_{-}$Taxes & $-T_{-}{ }_{-}$ & $-{ }_{-}^{0}-$ & 0 & $\stackrel{0}{-}$ & . & ${ }_{-}^{0}--$ & $-\stackrel{0}{-}-$ & $-{ }_{-}^{-T_{F}}$ & $-{ }_{-}^{0}$ & $\stackrel{+T}{-}_{-}$ & $\stackrel{0}{-}$ \\
\hline Int. on Loans & $-r_{h} L h t-1$ & $+r(1-z) L$ & 0 & $+r z L$ & 0 & 0 & 0 & $-r_{f} L f_{t-1}$ & 0 & 0 & 0 \\
\hline Return on Deriv. & 0 & 0 & 0 & $-f C D O$ & 0 & $+f C D O$ & 0 & 0 & 0 & 0 & 0 \\
\hline Return on Shares & $+R S H$ & 0 & 0 & 0 & & $-R S H$ & 0 & 0 & 0 & 0 & 0 \\
\hline Int. on Bonds & 0 & $+R B_{B}$ & 0 & 0 & 0 & $+R B_{I F}$ & 0 & 0 & 0 & $-R B$ & 0 \\
\hline Dividends & 0 & $-D i v_{B}$ & 0 & 0 & 0 & $+D i v_{B}$ & 0 & 0 & 0 & 0 & 0 \\
\hline Profits & $+\Pi_{H}$ & 0 & 0 & 0 & 0 & $-\Pi_{I F}$ & $+\Pi_{I F}$ & $-\Pi_{F}$ & $+\Pi_{F}$ & 0 & 0 \\
\hline \multicolumn{12}{|c|}{ Change in the stocks of } \\
\hline Deposits & $-\Delta D_{H}$ & 0 & $+\Delta D$ & 0 & 0 & 0 & $-\Delta D_{I F}$ & 0 & $-\Delta D_{F}$ & 0 & 0 \\
\hline Loans & $+\Delta L_{H}$ & 0 & $-\Delta(1-z) L$ & 0 & $-\Delta z L$ & 0 & 0 & 0 & $+\Delta L_{F}$ & 0 & 0 \\
\hline Derivatives & 0 & 0 & 0 & 0 & $+\triangle C D O$ & 0 & $-\triangle C D O$ & 0 & 0 & 0 & 0 \\
\hline Shares & $-\Delta S h$ & 0 & 0 & 0 & 0 & 0 & $+\Delta S h$ & 0 & 0 & 0 & 0 \\
\hline Bonds & & 0 & $-\Delta B_{B}$ & 0 & 0 & 0 & $-\Delta B_{I F}$ & 0 & 0 & $+\Delta B$ & 0 \\
\hline$\Delta$ Total & 0 & 0 & 0 & 0 & 0 & 0 & 0 & 0 & 0 & 0 & 0 \\
\hline
\end{tabular}

Table A.2: Aggregate Transaction Flow Matrix (Initial Situation) 


\section{References}

Abiad, A., Oomes, N. and Ueda, K. (2008), 'The quality effect: does financial liberalization improve the allocation of capital?', Journal of Development Economics 87(2), 270-282.

Arcand, J. L., Berkes, E. and Panizza, U. (2015), 'Too much finance?', Journal of Economic Growth $\mathbf{2 0}(2), 105-148$.

Atkinson, A. B., Piketty, T. and Saez, E. (2011), 'Top incomes in the long run of history.', Journal of Economic Literature 49(1), 3-71.

Beck, T., Demirguç-Kunt, A. and Levine, R. (2007), 'Finance, inequality and the poor', Journal of Economic Growth 12(1), 27-49.

BIS (2011), Basel iii: A global regulatory framework for more resilient banks and banking systems, BIS technical report 189, Bank for International Settlements.

Blanchard, O. (2009), The crisis: basic mechanisms, and appropriate policies, IMF Working Papers $09 / 80, \mathrm{IMF}$

Bordo, M. D. and Meissner, C. M. (2012), 'Does inequality lead to a financial crisis?', Journal of International Money and Finance 31(8), 2147-2161.

Botta, A., Caverzasi, E. and Tori, D. (2018), 'The macroeconomics of shadow banking', Macroeconomic Dynamics forthcoming.

Boyer, R. (2010), 'Is a finance-led growth regime a viable alternative to fordism? a preliminary analysis', Economy and Society 29(1), 111-145.

Brunnermeir, M. K. (2009), 'Deciphering the liquidity and credit crunch 2007-2008', Journal of Economic Perspectives 23(1), 70-100.

Cardaci, A. (2018), 'Inequality, household debt and financial instability: An agent-based perspective', Journal of Economic Behavior and Organization 149(C), 434-458.

Cardaci, A. and Saraceno, F. (2016), 'Inequality, financialisation and credit booms - a model of two crises', SEP Working Papers (2).

Caverzasi, E. and Godin, A. (2014), 'Stock-Flow Consistent Modeling trough the Ages', Cambridge Journal of Economics $\mathbf{1}(34)$.

Cecchetti, S. G. and Kharroubi, E. (2012), 'Reassessing the impact of finance on growth', BIS Working Paper (381).

Ciarli, T., Lorentz, A., Savona, M. and Valente, M. (2012), 'The role of technology, organisation, and demand in growth and income distribution', LEM Working Paper Series (6).

Claessens, S. and Perotti, E. (2007), 'Finance and inequality: channels and evidence', Journal of Comparative Economics 69(4), 748-773.

Clarke, G. R., Xu, C. and fu Zou, H. (2006), 'Finance and income inequality: What do the data tell us?', Southern Economic Journal 72(3), 578-796.

Cynamon, B. and Fazzari, S. (2008), 'Household debt in the consumer age ? source of growth and risk of collapse', Capitalism and Society $\mathbf{3}(2), 1$ ?30.

de Haan, J. and Sturm, J.-E. (2017), 'Finance and income inequality: a review a new evidence', European Journal of Political Economy 50, 171-190.

Denk, O. and Cournede, B. (2015), Finance and income inequality in oecd countries, OECD Economics Department Working Papers 1224, OECD. 
Dosi, G., Fagiolo, G., Napoletano, M. and Roventini, A. (2013), 'Income distribution, credit and fiscal policies in an agent-based keynesian model', Journal of Economic Dynamics 6 Control 37(8), 15981625.

Epstein, G. (2005), Introduction: Financialization and the world economy, in G.A.Epstein, ed., 'Financialization and The World Economy', Edward Elgar Publishing, pp. 3-16.

Fagiolo, G., Giachini, D. and Roventini, A. (2017), 'Innovation, finance, and economic growth: An agentbased approach', LEM Working Papers (30).

Fisher, I. (1933), 'The Debt-Deflation Theory of Great Depression', Econometrica 1-4, 337-357.

Fitoussi, J.-P. and Saraceno, F. (2010), 'Europe: How deep is the crisis? policy responses and structural factors behind diverging performances', Journal of Globalization and development 1(1), 1-19.

Fitoussi, J.-P. and Stiglitz, J. E. (2009), The way out of the crisis and the building of a more cohesive world, OFCE Document du Travail 2009-17, Centre du recherche en économie de Sciences Po.

Frank, R. (2005), 'Positional externalities cause large and preventable welfare losses', American Economic Association Papers and Proceedings 95(2), 137 ?141.

Garbade, K. and Ingber, J. (2005), 'The treasury auction process: Objectives, structure, and recent adaptations', Federal Reserve Bank of New York Current Issues in Economics and Finance 11(2), 1 ?11.

Goda, T. and Lysandrou, P. (2014), 'The contribution of wealth concentration to the subprime crisis: A quantitative estimation', Cambridge Journal of Economics 38(2), 301-327.

Godley, W. and Lavoie, M. (2007), Monetary Economics An Integrated Approach to Credit, Money, Income, Production and Wealth, Palgrave MacMillan, New York.

Gorton, G. and Metrick, A. (2012), 'Securitized banking and the run on repo', Journal of Financial Economics (104), 425-451.

IMF (2009), 'Global financial stability report navigating the financial challenges ahead', World Economic and Financial Surveys .

Kumhof, M., Rancière, R. and Winant, P. (2015), 'Inequality, leverage and crises', American Economic Review 105(3), 1217-1245.

Lauretta, E. (2018), 'The hidden soul of financial innovation: an agent-based modelling of home mortgage securitization and the finance-growth nexus', Economic Modelling 68(1), 51-73.

Law, S. and Singh, N. (2014), 'Does too much finance harm economic growth?', Journal of Banking and Finance 41, 36-44.

Levine, R. (2005), Finance and growth: Theory and evidence, in P. Aghion and S. Durlauf, eds, 'Handbook of Economic Growth', North-Hollad, pp. 866-934.

Lysandrou, P. (2011), 'Global inequality, wealth concentration and the subprime crisis: A marxian commodity theory analysis', Development and Change 42(1), 183-208.

Marglin, S. (1984), Growth, Distribution and Prices, Harvard University Press.

Mazzocchetti, A., Raberto, M., Teglio, A. and Cincotti, S. (2017), Securitization and business cycle: An agent based perspective, MPRA Paper 76760.

Nikolaidi, M. (2015), 'Securitization, wage stagnation and financial fragility: A stock-flow consistent perspective', Greenwich Papers in Political Economy (GPERC27).

Palagi, E., Napoletano, M., Roventini, A. and Gaffard, J.-L. (2017), 'Inequality, redistributive policies and multiplier dynamics in a agent-based model with credit rationing', Italian Economic Journal 3(3), 367-387. 
Piketty, T. (2014), Capital in the Twenty-First Century, Harvard University Press.

Rajan, R. G. (2010), Fault lines: How hidden fractures still threaten the world economy, Princeton University Press.

Rajan, R. G. and Zingales, L. (2003), 'The great reversals: the politics of financial development in the twentieth century', Journal of Financial Economics 69(1), 5-50.

Russo, A., Riccetti, L. and Gallegati, M. (2016), 'Increasing inequality, consumer credit and financial fragility in an agent based macroeconomic model', Journal of Evolutionary Economics 26(1), 25-47.

Shularick, M. and Taylor, A. M. (2012), 'Credit booms gone bust: Monetary policy, leverage cycles, and financial crises', The American Economic Review 102(2), 1029-1061.

Stiglitz, J. E. (2012), The Price of Inequality, Norton \& Co Inc.

Stiglitz, J. E. (2015a), The Great Divide: Unequal Societies and What We Can Do About Them, Norton \& Co Inc.

Stiglitz, J. E. (2015b), 'Inequality and economic growth', The Political Quarterly 86(S1), 134-155.

Stiglitz, J. E. (2016), New theoretical perspectives on the distribution of income and wealth among individuals, in J. E. Stiglitz and K. Basu, eds, 'Inequality and Growth: Patterns and Policy Volume I: Concepts and Analysis', Pallgrave Macmillan, chapter 1, pp. 1-71.

Stockhammer, E. (2015), 'Rising inequality as a cause of the present crisis', Cambridge Journal of Economics 39(3), 935-958.

Taylor, J. B. (2009), The financial crisis and the policy responses: An empirical analysis of what went wrong, NBER Working Papers 14631, National Bureau of Economic Research, Inc.

van Treeck, T. (2014), 'Did inequality cause the us financial crisis?', Journal of Economic Surveys 28(3), 421-448.

Wojnilower, A. (1980), 'The central role of credit crunches in recent financial history', Brookings Papers on Economic Activity 11 (2), 277-326. 